\title{
The Adoption of Blended E-learning Technology in Vietnam using a Revision of the Technology Acceptance Model
}

\author{
Khanh Ngo Nhu Tran \\ Vincent Mary School of Science and Technology, \\ Assumption University, Bangkok, Thailand
}

khanhtnn@dlu.edu.vn

\begin{abstract}
This study examines factors that determine the attitudes of learners toward a blended e-learning system (BELS) using data collected by questionnaire from a sample of 396 students involved in a BELS environment in Vietnam. A theoretical model is derived from previous studies and is analyzed and developed using structural equation modeling techniques. Several theoretical findings from previous studies are confirmed but there are new findings concerned with important indirect effects on the learner's attitude caused by (a) the extent to which the BELS provides flexible access to instructional/assessment media (System Functionality); (b) the individual's ability to use language as a studying tool (Language Capability); and (c) the extent of the interactions among students and faculty (Interaction). Each of these indirect effects operates by directly increasing the individual's belief that using the BELS is easy (Perceived Ease of Use) which in turn produces an improved attitude towards the BELS. Also, System Functionality has an important indirect effect on the learner's attitude to the BELS by increasing the learner's perceptions that the information and the manner in which it is presented in the BELS are appropriate (Content Feature), which then produces a definite improvement in the learner's attitude to the BELS. Based on the theoretical findings, a hierarchy of practical objectives and associated actions are suggested for improving the learner's attitude toward the BELS. These practical implications are expected to be of interest to education professionals and BELS developers and the actions relate directly or indirectly to (a) increasing the extent of the interactions among students and faculty; (b) increasing the individual's perception that the BELS is easy to use; (c) improving the learner's language skills; (d) ensuring that the BELS provides flexible access to instructional/assessment media; and (e) ensuring the appropriateness of the information and its presentation in the BELS.
\end{abstract}

Keywords: blended e-learning, technology acceptance, beliefs, attitude, structural equation modelling.

Material published as part of this publication, either on-line or in print, is copyrighted by the Informing Science Institute. Permission to make digital or paper copy of part or all of these works for personal or classroom use is granted without fee provided that the copies are not made or distributed for profit or commercial advantage AND that copies 1) bear this notice in full and 2) give the full citation on the first page. It is permissible to abstract these works so long as credit is given. To copy in all other cases or to republish or to post on a server or to redistribute to lists requires specific permission and payment of a fee. Contact Publisher@InformingScience.org to request redistribution permission.

\section{Introduction}

The Internet and information and communication technologies have transformed traditional teaching and learning techniques into new methods known as electronic learning or e-learning (Huynh $\&$ Le Thi, 2014). According to Garrison (2011), e-learning refers to the electronically mediated asynchronous and syn- 
chronous communication for purpose of constructing and confirming knowledge. E-learning is mainly associated with activities involving the simultaneous use of computers and interactive networks, and other terms which are used interchangeably with e-learning include Web-based learning, online learning, and distance learning. These terms have come to represent approaches with subtle but consequential differences (Tsai \& Machado, 2002). Although e-learning increases access flexibility, eliminates geographical barriers, and improves convenience and effectiveness for individualized and collaborative learning, certain shortcomings exist. Several studies have revealed disadvantages of e-learning, such as a lack of peer contact and social interaction, high initial costs for preparing multimedia content materials, substantial costs for system maintenance and updating, as well as the need for flexible tutorial support. Furthermore, learning online is a solo act for the most part, which may give the learners the feeling that they are acting completely alone (Chih-Min Ma \& Cheng, 2013; Wu, Tennyson, \& Hsia, 2010; Z. Yang \& Liu, 2007). The Internet allows the presentation of diverse content which can be a source of distraction and loss of concentration for some individuals. Consequently, face-to-face interaction with a teacher still plays an important role in a student's learning process (Žuvi-Butorac, Roncevi, Nemcanin, \& Nebi, 2011). Blended e-learning systems (BELS) have been proposed as promising alternative instructional solutions designed to relieve e-learning problems and increase the adoption of elearning (Graham, 2006). BELS is defined as a teaching system that integrates multiple learning delivery methods including a common face-to-face classroom environment with asynchronous and/or synchronous online learning (Wu et al., 2010). These methods are combined in such a way that one is strengthened by the other so that the overall result is better than the best of any of the constituent elements (Garrison, 2011). This mode of teaching/learning can eliminate time, place, and situational barriers, while still enabling high quality interactions between teachers and students (Jeffrey, Milne, Suddaby, \& Higgins, 2014). Several recent studies indicated that the use of blended e-learning in higher education might have a positive effect in reducing dropout rates as well as in improving learning outcomes (Ferriman, 2013; López-Pérez, Pérez-López, \& Rodrlguez-Ariza, 2011; Y.-T. C. Yang, Chuang, Li, \& Tseng, 2013). A high degree of utility, motivation and satisfaction is perceived from a blended learning environment, which could lead students to have a positive attitude towards learning (López-Pérez et al., 2011).

Since the year 2000, the Vietnam Government has identified e-learning as a key factor to drive educational growth and several policies have been issued in an effort to promote the development of e-learning in Vietnam (Anh, 2012). In order to satisfy the prerequisites for a growing demand for e-learning in the education sector, the government has an agreement with the telecom operator Viettel to improve the school systems' information technology infrastructure, which provides free Internet access ( 72 percent of which is broadband) to all 29,500 schools reaching over 26 million students and teachers in the country (AmbientInsight, 2014). In May 2014, the Ministry of Education and Training and Viettel signed the phase 2 agreement to use the deployed infrastructure to enhance e-education with various ICT applications such as e-books, e-schools, and e-learning in the period 2014-2020 (BaoMoi.com, 2014). According to the forecast of Ambient Insight (2014), in the period 2013-2018 Vietnam will become one of the top ten countries with the highest selfpaced e-learning growth rates in the world as well as in the Asia region.

However, the success of e-learning not only relies on the support of government and other organizations but also on its adoption and acceptance among learners. Porter, Graham, Spring, \& Welch (2014) showed that the attraction of potential adopters, including student adopters, is one of the important phases in blended learning implementation. E-learning in Vietnam is in an early stage of development and there have been only a limited number of studies on e-learning acceptance in Vietnam (Huynh \& Le Thi, 2014; Nguyen, Nguyen, \& Cao, 2014; Vu, Nguyen, \& Lin, 2011). Consequently, there is a need for further in-depth research on student's perception of BELS environment to be undertaken in the Vietnam context because this mode of teaching/learning is different from a traditional classroom and virtual e-learning environment. 
In order to strengthen understanding of e-learning adoption in Vietnam this study aims to investigate the primary factors that influence student attitudes toward BELS using a revised of Technology Acceptance Model (TAM). In particular, the study addresses four related research questions:

Q1. What are the factors that affect a student's attitude towards using BELS?

Q2. What are the relationships among the factors identified in Question 1?

Q3. Which relationships identified in Question 2 represent significant causal effects?

Q4. What are the theoretical and practical implications of the findings?

\section{Literature Review and Hypothesis Development}

The literature review includes an overview of previous studies related to the individual's elearning acceptance. Studies related to influential models and important variables are examined in order to develop the theoretical model of a student's attitude towards BELS used in this study which represents the research hypotheses for the study.

\section{Overview of Previous Studies}

Table 1 presents a summary of previous studies conducted both outside and inside Vietnam from which this research draws its support for the proposed theoretical research model.

Table 1: Previous studies on individual's e-learning acceptance and the role of individual differences in technology acceptance

\begin{tabular}{|l|l|}
\hline \multicolumn{1}{|c|}{ Project Focus } & \multicolumn{1}{|c|}{ References } \\
\hline Accessing the acceptance of a blended learning university course & $\begin{array}{l}\text { Tselios, Daskalakis, \& } \\
\text { Papadopoulou (2011) }\end{array}$ \\
\hline Explore behavioral intentions toward blended learning & Hsieh, Lu, \& Lee (2014) \\
\hline Re-assess students' perception on multimedia learning system & Saadé, Nebebe, \& Tan (2007) \\
\hline Analysis student's e-learning acceptance & Park (2009) \\
\hline Motivational factors that influence the acceptance of Moodle & Sánchez \& Hueros (2010) \\
\hline $\begin{array}{l}\text { The role of individual differences in new information technologies ac- } \\
\text { ceptance }\end{array}$ & Agarwal \& Prasad (1999) \\
\hline $\begin{array}{l}\text { Relating the five-factor personality model to technology acceptance and } \\
\text { use }\end{array}$ & Devaraj, Easley, \& Crant (2008) \\
\hline $\begin{array}{l}\text { The influence of personality factors on the core constructs of the Tech- } \\
\text { nology Acceptance Model }\end{array}$ & $\begin{array}{l}\text { Svendsen, Johnsen, Almås- } \\
\text { Sørensen, \& Vittersø (2013) }\end{array}$ \\
\hline Determinants of Intention to Use eLearning program & Punnoose (2012) \\
\hline The influence of system characteristics on e-learning use & Pituch \& Lee (2006) \\
\hline Antecedents and consequences of e-learning acceptance & Cheng (2011) \\
\hline Student satisfaction in a blended e-learning system environment & Wu et al. (2010) \\
\hline $\begin{array}{l}\text { Constructs related to community college student satisfaction in blended } \\
\text { learning }\end{array}$ & Sorden \& Munene (2013) \\
\hline $\begin{array}{l}\text { The Mediating Role of the Perceived Usefulness in the Acceptance of } \\
\text { E-learning }\end{array}$ & Huynh \& Le Thi (2014) \\
\hline $\begin{array}{l}\text { The acceptance of E-learning of graduate students of offshore programs } \\
\text { in Vietnam }\end{array}$ & Vu et al. (2011) \\
\hline
\end{tabular}

In Table 1, the unit of analysis in all of the studies was an individual. The studies were all explanatory in nature based on quantitative analyses of data collected by questionnaires. Most of the studies used the Technology Acceptance Model as the theoretical base except for Wu et al. (2010), which adopted a model derived from the Theory of Reasoned Action and Social Cognitive Theory, and Sorden \& Munene (2013), which only examined the relationships between social constructs and satisfaction based on a prior study's questionnaire. Also, from Table 1 it is seen 
that there is a lack of studies conducted in the context of Vietnam, especially research that investigated the adoption of BELS.

\section{Model Variables}

The Technology Acceptance Model (TAM) proposed by Davis (1985) is one of the most influential models of user acceptance of information systems. This model is an adaptation of the Theory of Reasoned Action (TRA), which explains and predicts the behaviors of people in a specific situation. The key purpose of TAM is to provide an explanation of the determinants of computer acceptance that is, in general, capable of explaining user behavior across a broad range of enduser computing technologies and user populations, while at the same time being both parsimonious and theoretically justified (Davis, Bagozzi, \& Warshaw, 1989). In particular, TAM examines the impact of external variables on internal beliefs, attitudes, and intentions.

Because the aim of this research is to examine the learner's attitude in the context of BELS, three variables in the TAM were selected for the theoretical model: Perceived Usefulness; Perceived Ease of Use; and Attitude. Perceived Usefulness is defined as the degree to which an individual believes that using a particular system would enhance their job performance. Perceived Ease of Use is the degree to which an individual believes that using a system would be free of physical and metal effort. Attitude refers to positive or negative feelings of individuals about performing a target behavior (Davis et al., 1989).

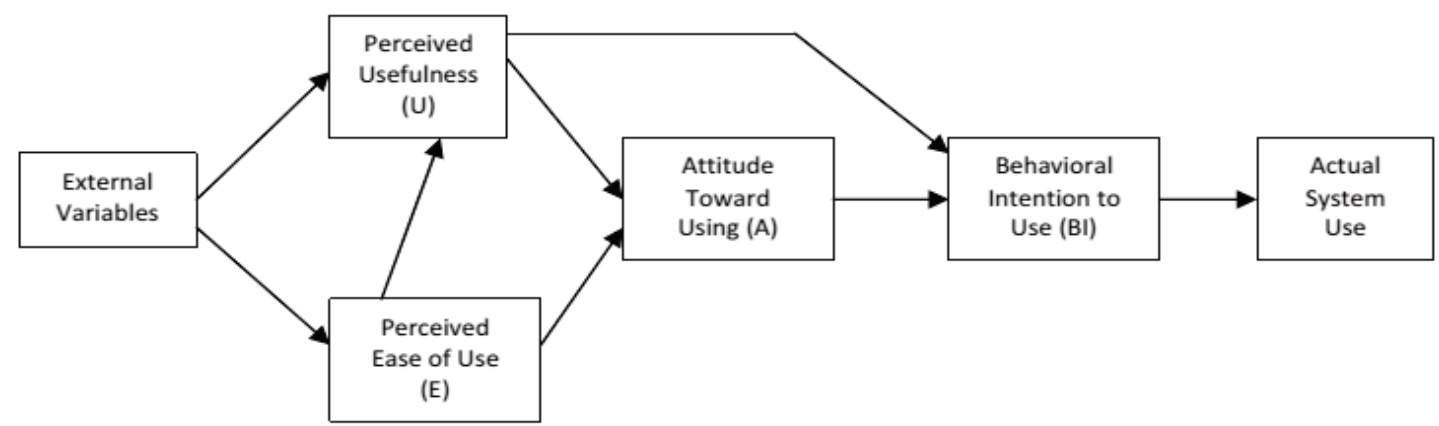

Figure 1: Technology acceptance model (TAM) [adapted from Davis et al. (1989)].

As shown in Figure 1, TAM postulates that the attitude toward using a system is determined by Perceived Usefulness and Perceived Ease of Use, while Perceived Usefulness and Perceived Ease of Use are influenced by external variables. Based on TAM, several previous studies in e-learning adoption and acceptance found that Perceived Usefulness and Perceived Ease of Use have a significant direct effect on attitude towards using an e-learning system (Cheng, 2011; Hsieh et al., 2014; Park, 2009; Saadé et al., 2007; Sánchez \& Hueros, 2010; Tselios et al., 2011). In BELS context, Tselios et al. (2011) and Hsieh et al. (2014) showed that Perceived Usefulness and Perceived Ease of Use play important roles in affecting student attitude. These researchers also found support for the effect of Perceived Ease of Use on the Perceived Usefulness of an e-learning system. Wu, Hsia, Liao, \& Tennyson (2008) showed that Perceived Value and Perceived Ease of Use had positive effects on a student's Attitude toward BELS where Perceived Value had a similar meaning to Perceived Usefulness. Huynh \& Le Thi (2014) investigated the effect of Perceived Usefulness and Perceived Ease of Use on the acceptance of e-learning in Vietnam. The findings indicated that students' perceived usefulness and ease of use positively affected their acceptance of e-learning for study. The link between students' perceived ease of use and acceptance of elearning was also mediated by their perception on the usefulness. 
Consequently, the following three hypotheses were formulated:

H1: Perceived Usefulness has a significant positive direct effect on Attitude.

H2: Perceived Ease of Use has a significant positive direct effect on Attitude

H3: Perceived Ease of Use has a significant positive direct effect on Perceived Usefulness.

Although TAM may be used to examine BELS acceptance, more studies based on TAM need to be conducted in various countries to investigate possible cultural and individual differences as well as different educational approaches and goals (Tselios et al., 2011). Researchers have extended TAM in three primary ways to provide greater understanding and explanatory power: introducing factors from related models (e.g., subjective norm, perceived behavioral control, and self-efficacy); introducing additional or alternative belief factors (mostly diffusion of innovation theory such as trialability, compatibility, visibility or result demonstrability); and examining external variables that affect Perceived Usefulness and Perceived Ease of Use such as personality traits, demographics and system characteristics (Wixom \& Todd, 2005). Using the third approach, this study incorporates external factors classified into three groups: System characteristics, Sociocultural factors, and Individual differences.

\section{System characteristics}

The role of system characteristics in predicting user beliefs and acceptance has been posited in many prior e-learning adoption studies (Cheng, 2011). Among possible system characteristics, several studies have argued that System Functionality and Content Feature influence the effectiveness of computer-mediated learning (Wu et al., 2010).

System Functionality refers to the perceived ability of an e-learning system to provide flexible access to instructional and assessment media that allow students to access course content, turn in homework assignments, and complete tests and quizzes online (Pituch \& Lee, 2006). Previous studies indicate that system functionality significantly affected user beliefs in various computerrelated contexts included e-learning (Hong, Thong, Wong, \& Tam, 2002; Pituch \& Lee, 2006; Venkatesh \& Davis, 2000). Cheng (2011) found that both belief constructs of TAM (Perceived Usefulness and Perceived Ease of Use) were positively affected by system functionality. Functionality of the e-learning system can be beneficial for learners to cultivate their interest in learning and so learners perceive that the system is easier to use and more useful.

Consequently, the following two hypotheses were formulated:

H4: System Functionality has a significant positive direct effect on Perceived Usefulness. H5: System Functionality has a significant positive direct effect on Perceived Ease of Use.

Content Features are defined as the characteristics and presentation of course content and information (Zhang, Keeling, \& Pavur, 2000). Content is used to identify various divergent formats and types of information. For e-learning systems, content features may include text, hypertext, graphics, audio and video, computer animations and simulations, embedded tests, or multimedia information (Wu et al., 2010). In the BELS context, Wu et al. (2010) found that learners' perceptions of high levels of system functionality and content feature lead to high levels of performance expectations for BELS. Content feature also depends on the system functionality of BELS and high quality system functionality of BELS can promote the delivery and access of diverse content features (Wu et al., 2010).

Consequently, the following two hypotheses were formulated:

H6: Content Feature has a significant positive direct effect on Perceived Usefulness.

H7: System Functionality has a significant positive direct effect on Content Feature. 


\section{Socio-cultural factors}

By extending the TAM, Venkatesh \& Davis (2000) showed that social influence processes significantly influenced user acceptance. In computer-mediated instructional design, there is an increasing focus on facilitating human interaction in the form of online collaboration, virtual communities, and instant messaging in the BELS context (Graham, 2006). Collaborative learning occurs when learners interact to construct common meaning and knowledge. Sorden \& Munene (2013) examined the role of collaborative learning in a community college blended learning environment and found a high, positive relationship between this construct and students' satisfaction. In addition, Kathrin (2007, as cited in Vu et al., 2011) suggested that the evaluation of e-learning might depend on socio-cultural factors including the learner, the teacher, the learning environment, and the didactical method. Among socio-cultural factors, language is also one of the most important constraints on portability of educational software leading to the influence of e-learning adoption (Vu et al., 2011). Mukkavilli (2008) indicated language difference as one of the factors affecting e-learning in the organization.

This category includes three factors which were expected to affect the acceptance of BELS in Vietnam: language capability, interaction, and learning climate.

Language Capability is a cultural tool that plays an important role in global e-learning (AlHuwail, Al-Sharhan, \& Al-Hunaiyyan, 2007). The lack of Vietnamese language software affects the use of the Internet in educational applications ( $\mathrm{Vu}$ et al., 2011). Because most of the learning materials in the BELS environment in this study were presented in English, Language capability was defined as the ability to use English as one of studying tools in BELS. Although BELS may engage local instructors to facilitate learning through translation of the learning materials, the student's perceptions of the usefulness and ease of use of BELS can be influenced by their language capability.

Consequently, the following two hypotheses were formulated:

H8: Language Capability has a significant positive direct effect on Perceived Usefulness. H9: Language Capability has a significant positive direct effect on Perceived Ease of Use.

Interaction is defined as the social interactions among students, the interactions between faculty and students, and the collaboration in learning (Chou \& Liu, 2005).

Learning Climate refers to the learning atmosphere in the context of BELS (Prieto \& Revilla, 2006). Wu et al. (2010) suggested that interaction and learning climate are important antecedents of beliefs about using a BELS. The interactions among students, between faculty and students, and learning collaboration are the keys to learning process effectiveness. Moreover, the emotional learning climate is an important indicator of learning effectiveness (Wu et al., 2010). Pituch \& Lee (2006) showed that social interaction has a direct effect on both perceived usefulness and the usage of e-learning systems. In a BELS environment, Wu et al. (2010) showed that interaction was positively associated with performance expectations and the learning climate. The learning climate was found to influence the level of learning satisfaction with BELS.

Consequently, the following three hypotheses were formulated:

H10: Interaction has a significant positive direct effect on Perceived Usefulness.

H11: Learning Climate has a significant positive direct effect on Attitude.

H12: Interaction has a significant positive direct effect on Learning Climate.

\section{Individual differences}

Individual differences are user factors that include traits such as personality and demographic variables, as well as situational variables that account for differences attributable to circumstances 
such as experience and training (Agarwal \& Prasad, 1999). This category included Computer Self-efficacy and Personality Traits.

Computer Self-efficacy refers to the self-assessment of individual ability to apply computer skills to complete particular tasks (Compeau \& Higgins, 1995). This construct is derived from the self-efficacy construct in Social Cognitive Theory (SCT), defined as people's judgments of their capabilities to organize and execute courses of action required attaining designated types of performances. While TAM focuses on beliefs about the technology and the outcomes of using it, SCT includes other beliefs that might influence behavior, independent of perceived outcomes (Gong, Xu, \& Yu, 2004). Cheng (2011) and Punnoose (2012) found that computer self-efficacy positively affected Perceived Ease of Use when studying in e-learning mode. An individual's confidence in their computer-related knowledge and abilities may play important roles in affecting their judgment of the ease of the acceptance and usage of an e-learning system (Cheng, 2011). Wu et al. (2010) found that a high level of computer self-efficacy was positively associated with a high level of performance expectations for BELS, where performance expectations were defined as being similar to the Perceived Usefulness construct in the TAM. If students have higher computer self-efficacy and can control BELS, then they will perceive the systems' usefulness and value to be high, which in turn motivates their intention to use BELS (Wu et al., 2010).

Consequently, the following two hypotheses were formulated:

H13: Computer Self-efficacy has a significant positive direct effect on Perceived Ease of Use.

H14: Computer Self-efficacy has a significant positive direct effect on Perceived Usefulness.

Personality Traits are the dynamic and organized sets of characteristics of an individual that uniquely influence cognition, motivation, and behaviors and highlight the differences between the perceptions of individuals and their behaviors (Pervin, Cervone, \& John, 2008; Ryckman, 2008). A personality trait describes an individual's behavior that is relatively stable over certain period of time or in certain situations (Burger, 2008). The Big Five Personality Traits or the Five Factors Model (FFM) introduced in 1985 by McCrea and Costa is considered to be a comprehensive parsimonious model of personality (Costa \& McCrae, 1992) and the most useful taxonomy in personality research (Barrick, Mount, \& Judge, 2001). The FFM consists of five factors: Agreeableness, Conscientiousness, Extraversion, Neuroticism, and Openness to experience.

Extraversion is described as being assertive, action oriented, and describes individuals who enjoy opportunities for excitement, attention drawing, and talking (Migliore, 2011). Svendsen et al. (2013) found that personality influenced behavioral intention (BI) both directly and mediated through the TAM beliefs. Personality can also influence the TAM beliefs without influencing BI. This personality trait is positively related to Perceived Usefulness and Perceived Ease of Use and the effect of extraversion on BI turns out to be fully mediated by these beliefs. Extraversion also was found to have a significant positive, direct, medium effect on Perceived Ease of Use in the study by Punnoose (2012). Individuals with high levels of extraversion have high levels of interaction, stimulation, and capacity for enjoyment. Consequently, their perception is that the elearning systems are easy to use (Punnoose, 2012).

Consequently, the following two hypotheses were formulated:

H15: Extraversion has a significant positive direct effect on Perceived Usefulness.

H16: Extraversion has a significant positive direct effect on Perceived Ease of Use.

Openness to experience is described as being intellectually curious, open to new ideas, and it involves imaginative and creative cognition styles (Migliore, 2011). Punnoose (2012) suggests that students who are responsible and intellectually curious may be more achievement oriented, 
hard-working, and competitive. They may indicate higher levels for the perceived of usefulness and the perceived ease of use of the learning system (Svendsen et al., 2013).

Consequently, the following two hypotheses were formulated:

H17: Openness to experience has a significant positive direct effect on Perceived Usefulness.

H18: Openness to experience has a significant positive direct effect on Perceived Ease of Use.

Conscientiousness refers to the way individuals control, regulate, and direct their impulses, as related to decision-making and action-oriented behaviors (Migliore, 2011). People who are very conscientious are more likely to carefully consider ways in which the use of technology will allow them to be more efficient and perform at a higher level at work. As the result, conscientiousness magnifies beliefs that technology will facilitate effective job performance (Devaraj et al., 2008). Punnoose (2012) found support for the significantly positive and direct effect of conscientiousness on perceived usefulness. A conscientious individual might find that e-learning is time saving, flexible learning, and useful (Punnoose, 2012).

Consequently, the following hypothesis was formulated:

H19: Conscientiousness has a significant positive direct effect on Perceived Usefulness.

Agreeableness is described as an individual's concern for cooperation and social harmony, and characteristics include being considerate, friendly, generous, helpful, and willing to compromise one's own interests for others (Migliore, 2011). Devaraj et al. (2008) found that agreeableness was positively associated with the perceived usefulness of technology. Agreeable personalities are more likely to be accommodating and cooperative when asked to consider a new technology and to focus more on positive and cooperative dimensions of the technology rather than those elements that may be less facilitative of performance (Devaraj et al., 2008).

Consequently, the following hypothesis was formulated:

H20: Agreeableness has a significant positive direct effect on Perceived Usefulness.

Neuroticism is described as excessive worry that causes mental distress, emotional suffering, and an inability to cope with day-to-day life activities (Migliore, 2011). Devaraj et al. (2008) found that neuroticism is negatively associated with beliefs about the perceived usefulness of technology. Neurotic personalities are likely to view technological advances in their work as threatening and stressful, and this might generalize to negative beliefs about the perceived usefulness of technology (Devaraj et al., 2008).

Consequently, the following hypothesis was formulated:

H21: Neuroticism has a significant negative direct effect on Perceived Usefulness.

\section{Theoretical Model}

Figure 2 shows the theoretical model based on the variables and the causal relationships associated with the research hypotheses notated in the figure as $\mathbf{H 1}$ to $\mathbf{H 2 1}$. 


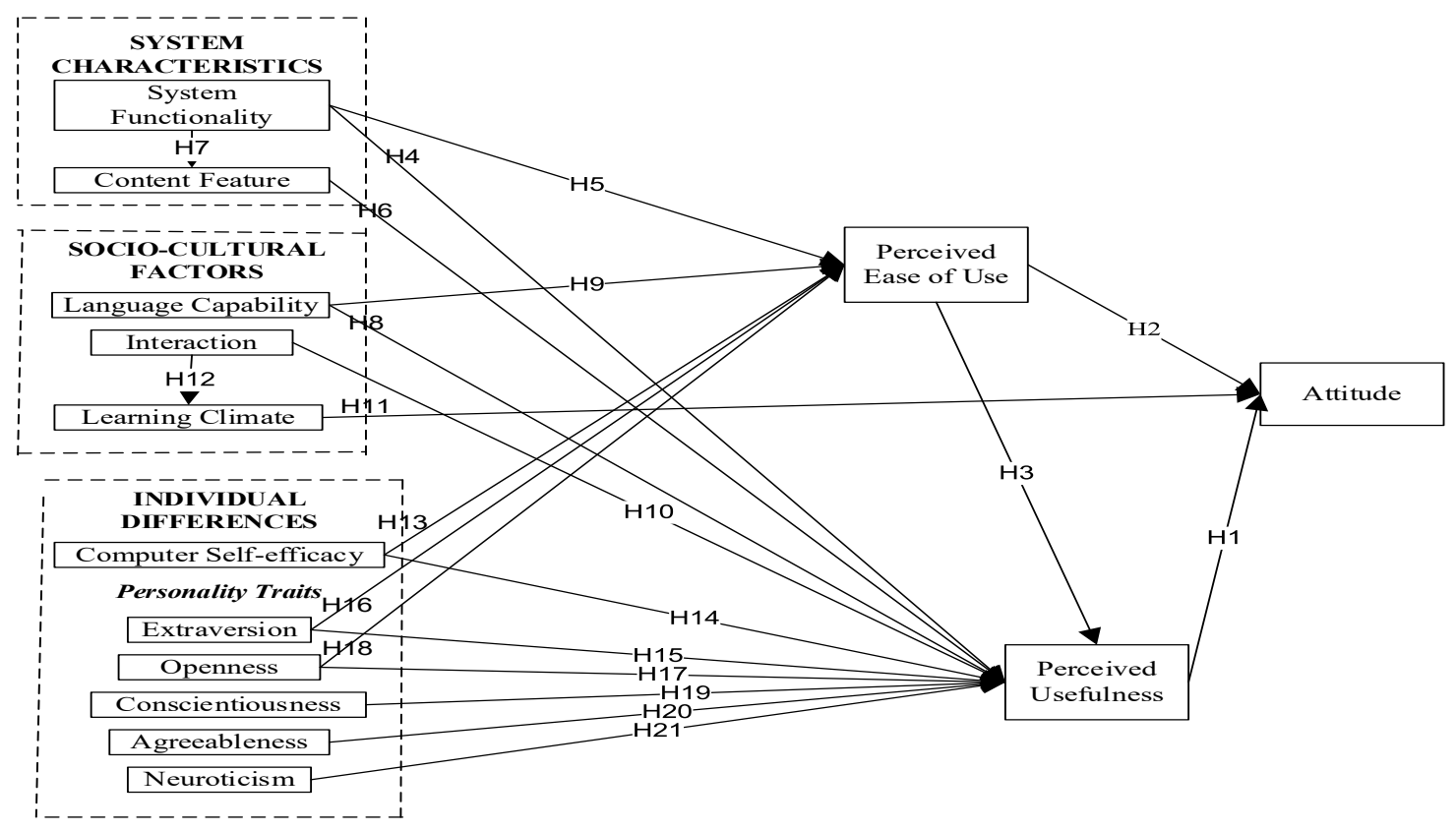

Figure 2: Theoretical model.

The model includes nine exogenous independent variables and five endogenous variables. As described previously the variables are classified in four categories representing System Characteristics, Socio-Cultural Factors, Individual Differences, and the TAM constructs (Perceived Ease of Use, Perceived Usefulness, and Attitude).

\section{Research Design and Methodology}

This study was partly basic and applied, partly descriptive and mainly explanatory, and crosssectional in time. The research employed descriptive statistical techniques for data preparation and preliminary analyses and structural equation modeling (SEM) techniques for the analysis and development of a theoretical model which was derived from existing theory. The unit of analysis was an individual undertaking Cisco Networking Academy's training programs in Vietnam using BELS. This is a comprehensive blended e-learning program that combines a centralized curriculum and standards-based testing delivered over the Internet with local instruction (Dennis et al., 2006).

The need for participants to be currently involved in the use of BELS was considered to be very important in relation to the validity and reliability of the study. The participants were all of Vietnamese nationality and at least 18 years of age. They had experience in using BELS as part of the Cisco Networking Academy's training program conducted in educational institutions in three urban areas in Vietnam. The size of this target population was approximately 12,000 individuals and the minimum sample size based on 5 percent precision and a 95 percent confidence level was determined to be 390 (Israel, 2013). This sample size also adequately satisfied the sample size needed to ensure the validity of the statistical techniques used study especially the use of SEM analysis techniques.

A self-administered structured questionnaire was designed in two sections. Section 1 presented questions designed to measure four variables (Age, Gender, Level of Education, and Experience with BELS) which were used to determine a personal profile of the respondents. Section 2 included questions related to the 14 variables involved in the research hypotheses H1 to $\mathbf{H 2 1}$ and shown in Figure 2. Each of these variables is a latent variable measured with more than one indi- 
cator where each indicator corresponds with a separate question in the questionnaire. Table 2 shows the names and symbols used for each of these variables and their indicators. In addition, a reference is provided to an existing measuring instrument for each variable.

Table 2: Measurement for latent model variables

\begin{tabular}{|l|l|l|}
\hline \multicolumn{1}{|c|}{ Variable (Symbol) } & \multicolumn{1}{c|}{ Indicators } & \multicolumn{1}{c|}{ Existing Measuring Instrument } \\
\hline System Functionality (SF) & SF1, SF2, SF3 & Wu et al. (2010) \\
\hline Content Feature (CF) & CF1, CF2, CF3 & Wu et al. (2010) \\
\hline Language Capability (LAC) & LAC1, LAC2, LAC3 & Vu et al. (2011) \\
\hline Interaction (I) & I1, I2, I3 & Wu et al. (2010) \\
\hline Learning Climate (LC) & LC1, LC2, LC3, LC4 & Wu et al. (2010) \\
\hline Computer Self-efficacy (CSE) & CSE1, CSE2, CSE3 & Wu et al. (2010) \\
\hline Extraversion (EX) & EX1, EX2, EX3, EX4 & Donnellan, Oswald, Baird, \& Lucas (2006) \\
\hline Openness to Experience (OE) & OE1, OE2, OE3, OE4 & Donnellan et al. (2006) \\
\hline Conscientiousness (CO) & CO1, CO2, CO3, CO4 & Donnellan et al. (2006) \\
\hline Agreeableness (AG) & AG1, AG2,AG3,AG4 & Donnellan et al. (2006) \\
\hline Neuroticism (NE) & NE1, NE2, NE3, NE4 & Donnellan et al. (2006) \\
\hline Perceived Usefulness (PU) & PU1, PU2, PU3 & Park (2009) \\
\hline Perceived Ease of Use (PE) & PE1, PE2, PE3 & Park (2009) \\
\hline Attitude (AT) & AT1, AT2, AT3 & Park (2009) \\
\hline
\end{tabular}

In Table 2 each indicator is measured on a 5 point Likert scale, and these measures were treated as interval scale measures in analyses. Existing measuring instruments were used to identify questions related to the indicators for the latent variables. However, these questions needed to be modified from the form they took in the context of the previous study where they were used so that they were appropriate for measuring the same variables but in the context of the use of BELS. The use of existing measuring instruments was expected to enhance the reliability and validity of the measures of the variables.

The questionnaire was prepared in both the English and Vietnamese languages. Both language versions of the questionnaire were reviewed by a focus group of five users of BELS and suggested modifications were included in revised versions of the questionnaire. The revised Vietnamese language version was then used in a pilot study with a sample of ten suitable participants. Their responses and comments were noted and any modifications were incorporated into the final versions of the questionnaire. The final Vietnamese language version was then used in the full study. A notated version of the questionnaire is included in the Appendix.

The questionnaire was distributed to the members of the target population by contacting five universities randomly selected from those in the three urban areas in Vietnam where the Cisco Networking Academy program was conducted. At each of these five sites the responsible instructor was contacted, introduced to the purpose of the study, and fully briefed on the nature of the questionnaire and its administration. Each site was asked to have 100 questionnaires completed by randomly selected students currently studying the BELS Cisco Networking Academy program.

\section{Data Preparation and Preliminary Data Analysis}

\section{Data Preparation}

A sample of 449 questionnaires was obtained, which represented a 90 percent response rate from the target population. Ten percent (45) were checked for data entry errors in an SPSS worksheet and none were found. Twenty two were removed from the sample because they contained at least one unanswered question associated with an indicator for a model variable. A further 31 were removed because they included an outlier measure for at least one of the measures of the indica- 
tors for a model variable (i.e., a measure that differed from the mean by three standard deviations or more). Consequently, the final sample size was reduced to 396 which satisfied the requirement for a minimum sample size of 390 as described above.

The construct validity of the measures for the latent variables was examined using Principal Component factor analysis. Following Straub, Boudreau, and Gefen ( 2004), the measures of indicators with satisfactory construct validity have factor loadings of at least 0.4 in magnitude on only the factor representing the latent variable they are proposed to measure and the factor (latent variable) has an associated eigenvalue of at least 1 , which ensures that the latent variable is explaining a satisfactory amount of the overall variance among the measures.

The results for final factor analysis are shown in Appendix Table A1 and the following changes were required in order to arrive at the final set of latent variables and indicators shown in Table A1:

(a) The indicator AT1 for Attitude was removed because it measured both System Functionality and Attitude and not just Attitude.

(b) The three indicators (PU1, PU2, and PU3) for Perceived Usefulness measured the same construct as the remaining two indicators for Attitude (AT2 and AT3). Consequently, Perceived Usefulness was removed from the theoretical model and Attitude was measured by the five indicators AT2, AT3, PU1, PU2, and PU3.

(c) The four indicators for Learning Climate (LC1, LC2, LC3, and LC4) all measured exactly the same construct as the three indicators for Interaction (I1, I2, and I3). Consequently, Learning Climate was removed from the theoretical model and Interaction was measured by the seven indicators I1, I2, I3, LC1, LC2, LC3, and LC4.

The internal consistency (equivalence) reliability of the final set of indicators for each latent variable resulting from the factor analysis was assessed using Cronbach alpha coefficients shown in Appendix Table A2. These coefficients were all at least acceptable according to the interpretation provided by George \& Mallery (2003).

It is noted that it was not possible to obtain distinct measures for (a) Interaction and Learning Climate and (b) Perceived Usefulness and Attitude. In both cases the indicators measured one variable and not two distinct variables. This is a limitation on the study and the measurement of these four latent variables is a concern that needs to be addressed in future studies. It may be that the problem arose as a result of the translation of questions from previous English language instruments into the Vietnamese language.

The results of the factor and reliability analyses produced modifications to the theoretical model which are shown in the modified theoretical model in Figure 3 and the modified research hypotheses shown in Table 3.

From Table 3 it is seen that for the modified theoretical model in Figure 3, seven of the research hypotheses (H2, H5, H7, H9, H13, H16, and H18) are the same as in the original theoretical model in Figure 2. However, 10 new hypotheses (H22 - H31) were formulated and they were motivated by findings from the referenced previous studies. 


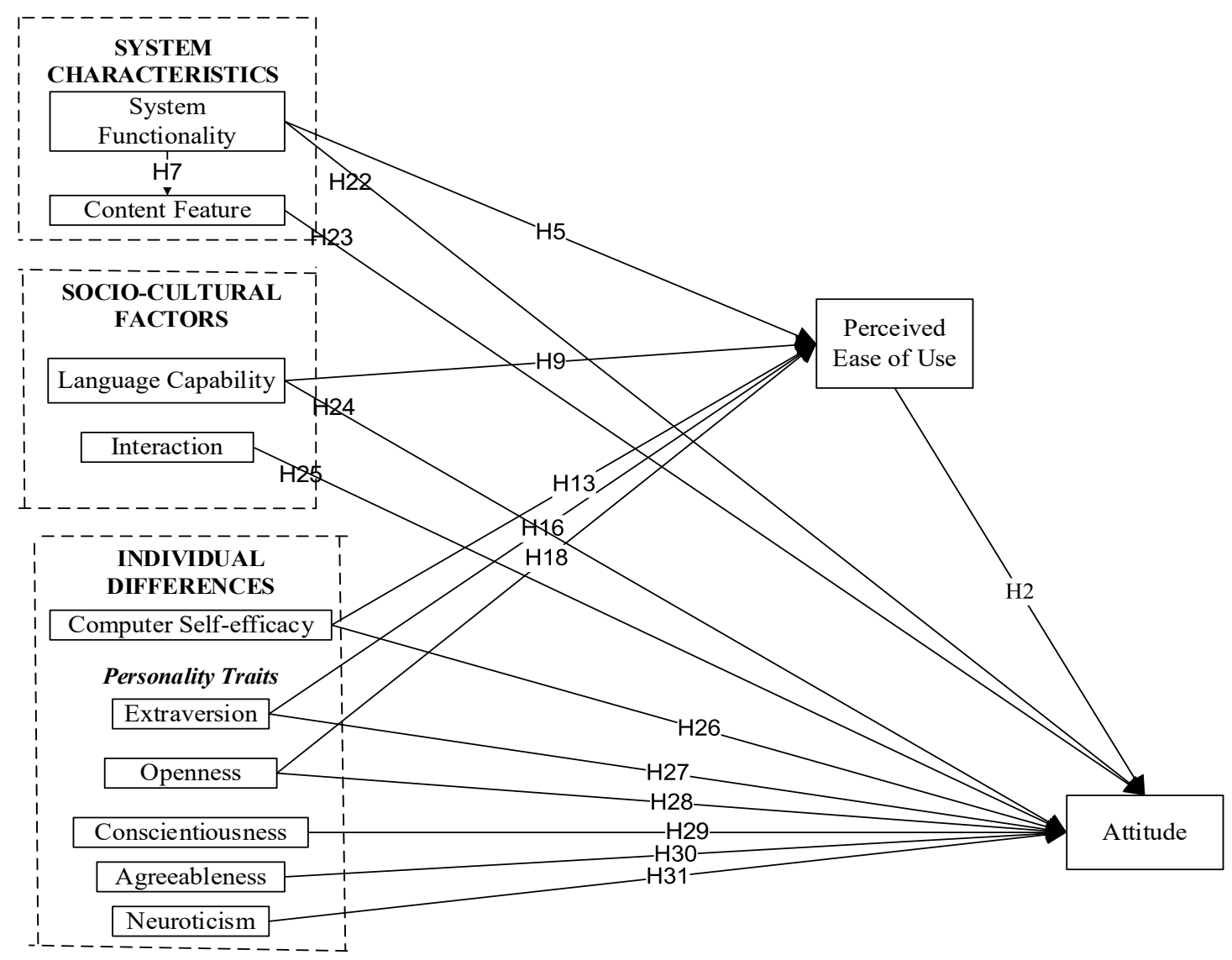

Figure 3: Modified theoretical model.

Table 3: Modified research hypotheses

\begin{tabular}{|l|l|l|}
\hline \multicolumn{2}{|c|}{ Hypothesis } & \multicolumn{1}{|c|}{ Reference } \\
\hline H2 & Perceived Ease of Use has a significant positive direct effect on Attitude & $\begin{array}{l}\text { Tselios et al. (2011); } \\
\text { Hsieh et al. (2014) }\end{array}$ \\
\hline H5 & $\begin{array}{l}\text { System Functionality has a significant positive direct effect on Perceived } \\
\text { Ease of Use }\end{array}$ & $\begin{array}{l}\text { Pituch \& Lee } \\
\text { (2006);(Cheng, 2011) }\end{array}$ \\
\hline H7 & $\begin{array}{l}\text { System Functionality has a significant positive direct effect on Content Fea- } \\
\text { ture }\end{array}$ & Wu et al. (2010) \\
\hline H9 & $\begin{array}{l}\text { Language Capability has a significant positive direct effect on Perceived Ease } \\
\text { of Use }\end{array}$ & Vu et al. (2011) \\
\hline H13 & $\begin{array}{l}\text { Computer Self-efficacy has a significant positive direct effect on Perceived } \\
\text { Ease of Use }\end{array}$ & $\begin{array}{l}\text { Cheng (2011); } \\
\text { Punnoose (2012) }\end{array}$ \\
\hline H16 & Extraversion has a significant positive direct effect on Perceived Ease of Use & $\begin{array}{l}\text { Svendsen et al. (2013); } \\
\text { Punnoose (2012) }\end{array}$ \\
\hline H18 & $\begin{array}{l}\text { Openness to Experience has a significant positive direct effect on Perceived } \\
\text { Ease of Use }\end{array}$ & Svendsen et al. (2013) \\
\hline H22 & System Functionality has a significant positive direct effect on Attitude & $\begin{array}{l}\text { Pituch \& Lee (2006); } \\
\text { Wu et al. (2010) }\end{array}$ \\
\hline H23 & Content Feature has a significant positive direct effect on Attitude & Wu et al. (2010) \\
\hline H24 & Language Capability has a significant positive direct effect on Attitude & Vu et al. (2011) \\
\hline H25 & Interaction has a significant positive direct effect on Attitude & Wu et al. (2010) \\
\hline H26 & Computer Self-efficacy has a significant positive direct effect on Attitude & Wu et al. (2010) \\
\hline H27 & Extraversion has a significant positive direct effect on Attitude & Svendsen et al. (2013) \\
\hline H28 & Openness to Experience has a significant positive direct effect on Attitude & Devaraj et al. (2008) \\
\hline
\end{tabular}




\begin{tabular}{|l|l|l|}
\hline \multicolumn{2}{|c|}{ Hypothesis } & \multicolumn{1}{c|}{ Reference } \\
\hline H29 & Conscientiousness has a significant positive direct effect on Attitude & $\begin{array}{l}\text { Devaraj et al. (2008); } \\
\text { Punnoose (2012) }\end{array}$ \\
\hline H30 & Agreeableness has a significant positive direct effect on Attitude & Devaraj et al. (2008) \\
\hline H31 & Neuroticism has a significant negative direct effect on Attitude & Devaraj et al. (2008) \\
\hline
\end{tabular}

\section{Profile of the Respondents}

From the responses to the items in section 1 of the questionnaire, it was found that: 87 percent of the respondents were males; 66 percent had previous experience with BELS; the average age of respondents was 23 years with 50 percent of age of 18-22 years 41 percent of age 23-27 years; and nearly 90 percent of respondents held a diploma or a bachelor degree. In summary, it was considered that the sample included individuals who were mature, well educated, and had sufficient experience to be able to provide valid and reliable responses to the questionnaire items.

\section{Descriptive Preliminary Analyses}

The values of descriptive statistics for each of the model variables are show in the Appendix Table A3. In addition to determining these statistics for the indicators of the latent variables, each of the latent variables was reduced to a single interval scale variable with values determined for each respondent by computing the mean of the values that the respondent assigned to the indicators. Because of the satisfactory construct validity and reliability of the measures of the indicators these single scale measures of the latent variables were suitable for the purpose of the preliminary descriptive analyses reported below. However, for the SEM techniques used for the analysis and development of the modified theoretical model in Figure 3 the separate measures of the indicators were used.

It is noted from Appendix Table A3 that the magnitudes of the values for skewness and kurtosis of all the indicators for the model variables are within the acceptable limits of 3 and 7, respectively. As specified by Kline (2005) these limits must not be exceeded in order to ensure the valid use of the maximum likelihood estimation techniques that will be used below for the SEM analysis and development of the modified theoretical model. .

T-tests were used to examine the differences between the mean values of the model variables and the neutral value of 3 on their 5-point measurement scales which represents a no opinion response to the construct measured by the variable. The results showed that the mean values of all of the model variables were significantly above the neutral value except for Neuroticism where the mean was significantly below the neutral value $(\mathrm{p}<0.05)$. Consequently, the individuals had well balanced personalities and overall they had very positive feelings about the BELS system.

T-tests were used to compare the mean values of the model variables for males and females. None of the differences between the means for males and females were statistically significant ( $p$ $<0.05)$. T-tests were also used to compare the mean values of the model variables for respondents with and without prior BELS experience. The results showed that those with prior experience with BELS had a significantly higher mean value for the variable Language Capability $(\mathrm{p}<0.05)$ which meant that on average they were better able to use the English language as a studying tool in the BELS environment.

Appendix Table A4 shows the correlations among model variables. There are statistically significant correlations associated with the relationships between four exogenous variables (Content Feature, Interaction, Conscientiousness, and Agreeableness) and the endogenous variable Perceived Ease of Use which do not correspond to direct causal effects in the modified theoretical model in Figure 3. Although significant correlations do not guarantee significant causal effects and vice versa, they often suggest significant causal relationships. Consequently, these four sig- 
nificant correlations are noted here and will be examined carefully in the SEM analyses and development of the modified theoretical model in the next section.

\section{Model Analysis and Development}

The results of the SEM analysis and the development of the modified theoretical model in Figure 3 are reported here. The interpretation of these results is addressed completely in the discussion of the next section.

The model analyses and development used SEM techniques implemented with AMOS 18 computer software following the guidance provided by Kline (2005). The results of the SEM analysis of the direct effects in the modified theoretical model (Figure 3) are shown in Table 4.

Table 4: Direct effects in the modified theoretical model

\begin{tabular}{|l|c|c|c|c|}
\hline Direct Effect & $\begin{array}{c}\text { Unstandardized } \\
\text { Effect }\end{array}$ & $\begin{array}{c}\text { Statistical Significance } \\
\text { of Unstandardized Effect }\end{array}$ & $\begin{array}{c}\text { Standardized } \\
\text { Effect }\end{array}$ & $\begin{array}{c}\text { Magnitude of Stand- } \\
\text { ardized Effect }\end{array}$ \\
\hline $\mathrm{SF} \rightarrow \mathrm{PE}$ & .445 & $* * *$ & .390 & Medium \\
\hline $\mathrm{LAC} \rightarrow \mathrm{PE}$ & .233 & $* * *$ & .296 & Medium \\
\hline $\mathrm{SF} \rightarrow \mathrm{CF}$ & .489 & $* * *$ & .517 & Large \\
\hline $\mathrm{CSE} \rightarrow \mathrm{PE}$ & .046 & NS & .055 & Small \\
\hline $\mathrm{EX} \rightarrow \mathrm{PE}$ & .069 & $*$ & .107 & Medium \\
\hline $\mathrm{OE} \rightarrow \mathrm{PE}$ & .005 & $\mathrm{NS}$ & .009 & Small \\
\hline $\mathrm{SF} \rightarrow \mathrm{AT}$ & .017 & NS & .018 & Small \\
\hline $\mathrm{CF} \rightarrow \mathrm{AT}$ & .128 & $*$ & .131 & Medium \\
\hline $\mathrm{LAC} \rightarrow \mathrm{AT}$ & .046 & $\mathrm{NS}$ & .073 & Small \\
\hline $\mathrm{PE} \rightarrow \mathrm{AT}$ & .268 & $* * *$ & .332 & Medium \\
\hline $\mathrm{I} \rightarrow \mathrm{AT}$ & .431 & $* * *$ & .480 & Medium \\
\hline $\mathrm{CSE} \rightarrow \mathrm{AT}$ & .034 & $\mathrm{NS}$ & .051 & Small \\
\hline $\mathrm{EX} \rightarrow \mathrm{AT}$ & -.032 & $\mathrm{NS}$ & -.061 & Small \\
\hline $\mathrm{OE} \rightarrow \mathrm{AT}$ & -.024 & $\mathrm{NS}$ & -.051 & Small \\
\hline $\mathrm{CO} \rightarrow \mathrm{AT}$ & .028 & $\mathrm{NS}$ & .043 & Small \\
\hline $\mathrm{AG} \rightarrow \mathrm{AT}$ & -.029 & $\mathrm{NS}$ & -.039 & Small \\
\hline $\mathrm{NE} \rightarrow \mathrm{AT}$ & -.013 & $\mathrm{NS}$ & -.023 & Small \\
\hline $\mathrm{N}$ & & & & \\
\hline
\end{tabular}

Notes: (a) $*, * *$ or $* * *$ are used with unstandardized effects to indicate statistical significant at a level of $0.05,0.01$, or 0.001 , respectively, and NS indicates not statistically significant at a level of 0.05 or less; (b) Magnitudes of standardized effects are classified as small (S), medium (M), or large (L) (Cohen, 1988).

In Table 4 the shaded rows identify 10 effects that not statistically significant and are small in magnitude. The model fit may be improved if these were removed. All of the other direct effects are statistically significant at a level of 0.05 or less and are at least medium in magnitude. Table 5 presents fit statistics recommended by Kline (2005). The values of the fit statistics are satisfactory except for GFI, AGFI, and NFI and it is suggested that changes to the modified theoretical model may result in a simple final model with improved values for the fit statistics.

Table 5: Fit statistics for the modified theoretical model

\begin{tabular}{|c|c|c|c|c|c|c|c|c|c|}
\hline Model & $\mathbf{N}$ & $\begin{array}{c}\text { Normed Chi-square } \\
\text { NC }\left(\chi^{2} / \mathbf{d f}\right)\end{array}$ & RMR & GFI & AGFI & NFI & IFI & CFI & RMSEA \\
\hline \multirow{2}{*}{ Modified Theoretical Model } & & $1911.374 / 981=1.948$ & 0.031 & 0.816 & 0.788 & 0.856 & 0.924 & 0.923 & 0.049 \\
\hline & 396 & $\mathbf{R}^{2}$ : PE (36 percent), CF & $(27$ per & rcent), & AT $(6$ & 3 perce & & & \\
\hline
\end{tabular}

Note: $\mathrm{R}^{2}$ is the proportion of the variance of each endogenous variable that is explained by the variables affecting it. 
The 10 small and not statistically significant direct effects in Table 4 are candidates to be deleted from the model. Based on the discussion of correlations among model variables above the four direct effects Content Feature $\rightarrow$ Perceived Ease of Use, Interaction $\rightarrow$ Perceived Ease of Use, Conscientiousness $\rightarrow$ Perceived Ease of Use, and Agreeableness $\rightarrow$ Perceived Ease of Use are candidates to be included in the model. These 14 direct effects were made optional in the model forming a hierarchy of $2^{14}=16,384$ models which was analyzed using the Specification Search Facility available in AMOS software. From the results the model with the smallest value for Normed Chi-square (NC) was selected as the final model (Kline, 2005). The final model is shown in Figure 4.

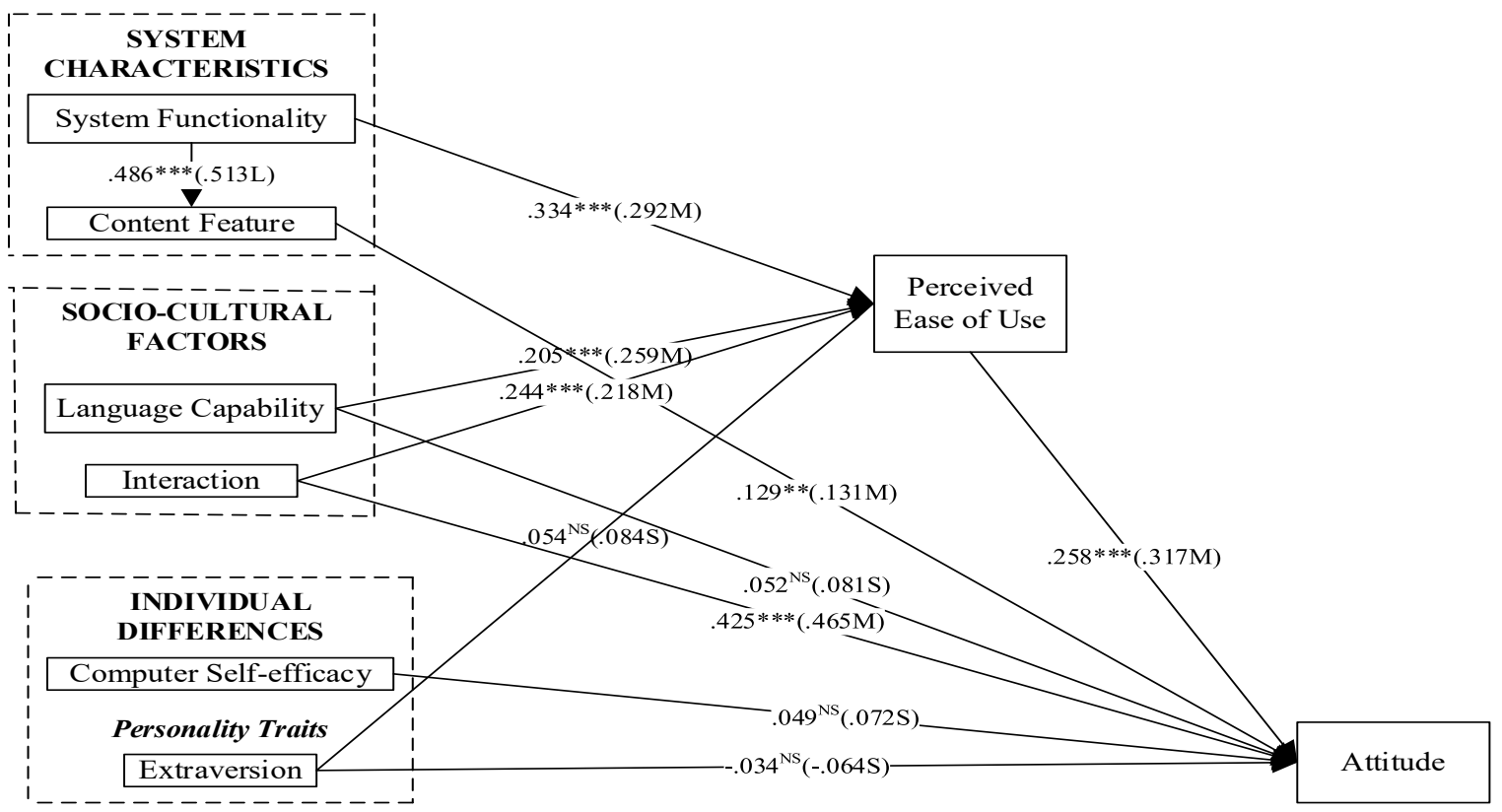

Figure 4: The final model.

In Figure 4 the notations used in Table 4 are shown for the direct effects. Unstandardized effects and their statistical significance are shown first followed in parentheses by standardized effects and their magnitudes. The fit statistics for the final model are shown in Table 6.

Table 6: Fit statistics for the final model

\begin{tabular}{|c|c|c|c|c|c|c|c|c|c|}
\hline Model & $\mathbf{N}$ & Normed Chi-square NC $\left(\chi^{2} / \mathrm{df}\right)$ & RMR & GFI & AGFI & NFI & IFI & CFI & RMSEA \\
\hline \multirow{2}{*}{ Final Model } & \multirow[b]{2}{*}{39} & $1903.971 / 987=1.929$ & 0.031 & 0.816 & 0.790 & 0.856 & 0.925 & 0.925 & 0.049 \\
\hline & & $2:$ PE (3 & AT $(6$ & 3 perce & & & & & \\
\hline
\end{tabular}

Note: $R^{2}$ is the proportion of the variance of each endogenous variable that is explained by the variables affecting it.

The fit statistics for the final model are satisfactory but only slightly better than those in Table 5 for the modified theoretical model. However, the important improvement is that the final model is simpler than the modified theoretical model because it has only 11 direct effects and eight variables compared to 17 direct effects and 12 variables in the modified theoretical model. A full analysis of all effects in the final model is displayed in Appendix Table A5.

\section{Discussion}

This section presents the interpretation and discussion of the findings of the study including the theoretical and practical contributions of the study and new findings as well as the limitations of the study. 


\section{Interpretation of Causal Effects}

Table 7 describes the nature of the effects in the final model based on the total of direct and indirect effects.

Table 7: Summary based on total effects in the final model

\begin{tabular}{|c|c|c|c|}
\hline \multirow{2}{*}{ Variable } & \multicolumn{2}{|c|}{ Intervening Variable } & Dependent Variable \\
\hline & Content Feature & Perceived Ease of Use & Attitude \\
\hline System Functionality & $\begin{array}{l}\text { Large, positive, } \\
\text { only direct }\end{array}$ & $\begin{array}{l}\text { Medium, positive, } \\
\text { only direct }\end{array}$ & $\begin{array}{l}\text { Medium, positive, } \\
\text { only indirect }\end{array}$ \\
\hline Language Capability & Nil & $\begin{array}{l}\text { Medium, positive, } \\
\text { only direct }\end{array}$ & $\begin{array}{l}\text { Medium, positive, } \\
\text { mainly indirect }\end{array}$ \\
\hline Interaction & Nil & $\begin{array}{l}\text { Medium, positive, } \\
\text { only direct }\end{array}$ & $\begin{array}{l}\text { Large, positive, } \\
\text { mainly direct }\end{array}$ \\
\hline Computer Self-efficacy & Nil & Nil & $\begin{array}{c}\text { Small, positive, } \\
\text { only direct }\end{array}$ \\
\hline Extraversion & Nil & $\begin{array}{c}\text { Small, positive, } \\
\text { only direct }\end{array}$ & $\begin{array}{l}\text { Small, negative, } \\
\text { mainly direct }\end{array}$ \\
\hline Content Feature & Nil & Nil & $\begin{array}{l}\text { Medium, positive, } \\
\text { only direct }\end{array}$ \\
\hline Perceived Ease of Use & Nil & Nil & $\begin{array}{l}\text { Medium, positive, } \\
\text { only direct }\end{array}$ \\
\hline
\end{tabular}

\section{Effects on the dependent and intervening variables}

Attitude is the dependent variable in this study and represents the extent of an individual's positive feelings about using a BELS. The variable Interaction has largest effect on Attitude followed in decreasing order by Perceived Ease of Use, System Functionality, Content Feature, and Language Capability. The indirect effect of System Functionality on Attitude is mediated by Perceived Ease of Use and Content Feature while the indirect effect of Language Capability on Attitude is mediated by the Perceived Ease of Use. Effects due to Computer Self-efficacy and Extraversion are only small and not statistically significant at level 0.05 or less.

Perceived Ease of Use represents the degree to which an individual believes that using BELS is free of cognitive effort. This perception is strongest for those who, in the following order of decreasing importance, find that BELS provides flexible access to course materials, believe that BELS is a collaborative learning environment supporting interaction among students and faculty, and have a good English language capability. These effects are positive, medium, and direct while Extraversion has only a small positive direct effect that is not statistically significant.

Content Feature represents the extent to which a person believes that the content, information, and presentation in BELS are appropriate. This endogenous variable is affected by System Functionality and the effect is large, positive, and direct. Consequently, the delivery of diverse content features to learners is highly dependent on the quality of system functionality.

\section{Effects due to the exogenous independent variables}

System Functionality represents the ability of BELS to provide flexible access to instructional and assessment media. This variable has positive effects on Content Feature, Perceived Ease of Use, and Attitude. The direct effects on Content Feature and Perceived Ease of Use are large and medium, respectively, while the effect on Attitude is only indirect through intervening variables (Content Feature and Perceived Ease of Use).

Language Capability refers to the degree to which an individual believes that he or she has appropriate English language proficiency to study with BELS. This has a positive, medium and di- 
rect effect on Perceived Ease of Use. The direct effect of Language Capability on Attitude is only slightly smaller in magnitude than the indirect effect. However, it is not statistically significant and the effect of Language Capability on Attitude is mainly indirect mediated by Perceived Ease of Use.

Interaction refers to the extent of interaction among students and faculty supporting collaborative learning. This variable has medium, positive, direct effects on Perceived Ease of Use and Attitude. It also has an indirect effect on Attitude mediated by Perceived Ease of Use but this effect is only small.

Computer Self-efficacy refers to the self-assessment of an individual's ability to apply computer skills in order to complete a task. It only has a small direct effect on Attitude and this effect is not statistically significant. Consequently, an individual's level of computer knowledge and related skills is of little importance in the determination of their attitude towards using BELS.

Extraversion represents the extent to which an individual is assertive, action oriented, and enjoys opportunities for excitement, attention drawing, and talking. Extraversion has a small positive direct effect on Perceived Ease of Use. This variable has a small, positive, indirect effect on Attitude through the mediation of Perceived Ease of Use. However, this positive effect is dominated by a direct negative effect on Attitude with the overall result that its total effect on Attitude is negative but small and none of these effects is statistically significant.

\section{Research Hypotheses and Comparisons with the Findings of Previous Studies}

Table 8 presents the decisions related to the 17 research hypotheses presented in Table 3 .

Table 8: Summary of the results of hypothesis testing

\begin{tabular}{|l|l|l|l|}
\hline \multicolumn{1}{|c|}{ Hypothesis } & \multicolumn{1}{|c|}{ Reference } & \multicolumn{1}{|c|}{ Decision } \\
\hline H2 & $\begin{array}{l}\text { Perceived Ease of Use has a significant positive direct effect } \\
\text { on Attitude }\end{array}$ & $\begin{array}{l}\text { Tselios et al. (2011); } \\
\text { Hsieh et al. (2014) }\end{array}$ & Supported \\
\hline H5 & $\begin{array}{l}\text { System Functionality has a significant positive direct effect } \\
\text { on Perceived Ease of Use }\end{array}$ & $\begin{array}{l}\text { Pituch \& Lee (2006); } \\
\text { (Cheng, 2011) }\end{array}$ & Supported \\
\hline H7 & $\begin{array}{l}\text { System Functionality has a significant positive direct effect } \\
\text { on Content Feature }\end{array}$ & Wu et al. (2010) & Supported \\
\hline H9 & $\begin{array}{l}\text { Language Capability has a significant positive direct effect } \\
\text { on Perceived Ease of Use }\end{array}$ & Vu et al. (2011) & Supported \\
\hline H13 & $\begin{array}{l}\text { Computer Self-efficacy has a significant positive direct effect } \\
\text { on Perceived Ease of Use }\end{array}$ & $\begin{array}{l}\text { Cheng (2011); } \\
\text { Punnoose (2012) }\end{array}$ & $\begin{array}{l}\text { Partially } \\
\text { Supported }\end{array}$ \\
\hline H16 & $\begin{array}{l}\text { Extraversion has a significant positive direct effect on } \\
\text { Perceived Ease of Use }\end{array}$ & $\begin{array}{l}\text { Svendsen et al. (2013); } \\
\text { Punnoose (2012) }\end{array}$ & $\begin{array}{l}\text { Partially } \\
\text { Supported }\end{array}$ \\
\hline H18 & $\begin{array}{l}\text { Openness to Experience has a significant positive direct } \\
\text { effect on Perceived Ease of Use }\end{array}$ & Svendsen et al. (2013) & Not Supported \\
\hline H22 & $\begin{array}{l}\text { System Functionality has a significant positive direct effect } \\
\text { on Attitude }\end{array}$ & $\begin{array}{l}\text { Pituch \& Lee (2006); } \\
\text { Wu et al. (2010) }\end{array}$ & $\begin{array}{l}\text { Partially } \\
\text { Supported }\end{array}$ \\
\hline H23 & $\begin{array}{l}\text { Content Feature has a significant positive direct effect on } \\
\text { Attitude }\end{array}$ & Wu et al. (2010) & Supported \\
\hline H24 & $\begin{array}{l}\text { Wanguage Capability has a significant positive direct effect } \\
\text { on Attitude }\end{array}$ & Vu et al. (2011) & $\begin{array}{l}\text { Partially } \\
\text { Supported }\end{array}$ \\
\hline H25 & $\begin{array}{l}\text { Interaction has a significant positive direct effect on Attitude } \\
\text { Supported }\end{array}$ \\
\hline H26 & $\begin{array}{l}\text { Computer Self-efficacy has a significant positive direct effect } \\
\text { on Attitude }\end{array}$ & Wu et al. (2010) & $\begin{array}{l}\text { Partially } \\
\text { Supported }\end{array}$ \\
\hline H27 & $\begin{array}{l}\text { Wxtraversion has a significant positive direct effect on } \\
\text { Attitude }\end{array}$ & Svendsen et al. (2013) & Not Supported \\
\hline
\end{tabular}




\begin{tabular}{|l|l|l|l|}
\hline \multicolumn{1}{|c|}{ Hypothesis } & \multicolumn{1}{|c|}{ Reference } & \multicolumn{1}{|c|}{ Decision } \\
\hline H28 & $\begin{array}{l}\text { Openness to Experience has a significant positive direct } \\
\text { effect on Attitude }\end{array}$ & Devaraj et al. (2008) & Not Supported \\
\hline H29 & $\begin{array}{l}\text { Conscientiousness has a significant positive direct effect on } \\
\text { Attitude }\end{array}$ & $\begin{array}{l}\text { Devaraj et al. (2008); } \\
\text { Punnoose (2012) }\end{array}$ & $\begin{array}{l}\text { Partially } \\
\text { Supported }\end{array}$ \\
\hline H30 & $\begin{array}{l}\text { Agreeableness has a significant positive direct effect on } \\
\text { Attitude }\end{array}$ & Devaraj et al. (2008) & $\begin{array}{l}\text { Partially } \\
\text { Supported }\end{array}$ \\
\hline H31 & $\begin{array}{l}\text { Neuroticism has a significant negative direct effect on } \\
\text { Attitude }\end{array}$ & Devaraj et al. (2008) & Not Supported \\
\hline
\end{tabular}

From Table 8 it is seen that:

(a) There was full support for six of the 17 hypotheses. These findings confirmed the importance of (i) the direct effect of System Functionality on Content Feature and Perceived Ease of Use and (ii) the direct effects of Content Feature, Interaction, and Perceived Ease of Use on Attitude.

(b) Contrary to the finding by Vu et al. (2011), Language Capability was found to have a significant positive direct effect on Perceived Ease of Use in this study. These results supported important parts of the structure of the theoretical model which was derived for previous studies and in particular elements derived from TAM.

(c) Seven hypotheses were partial supported which meant that although the hypothesized significant causal effect was not supported there was found to be a statistically significant correlation between the variables with the same direction as indicated for the hypothesized causal effect.

(d) There were four hypotheses for which there was no support. These hypotheses involved the three of the five personality traits: Openness to Experience, Extraversion, and Neuroticism. The other two traits, Conscientiousness and Agreeableness, were hypothesized to have significant positive direct effects on Attitude but there was only partial support for these two hypotheses as well as the hypothesized significant positive direct effect of Extraversion on Perceived Ease of Use. It appears that although personality traits have not played a major role in this study they have important relationships to Attitude and Perceived Ease of Use that should be examined in future studies.

In summary, there was full or partial support for 13 of the 17 research hypotheses derived from previous studies by Tselios et al. (2011), Hsieh et al. (2014), Pituch \& Lee (2006), Cheng (2011), Wu et al. (2010), Vu et al. (2011), Svendsen et al. (2013), Punnoose (2012), and Devaraj et al. (2008) which were the basis of the formulation of the theoretical model used in this study

\section{New Results Not Reported in Previous Studies}

Table 9 presents findings which have not been reported in previous studies. It is recommended that these relationships be examined again in future studies.

\section{Table 9: New findings}

1. System Functionality does not have a statistically significant positive direct effect on Attitude but it does have a statistically significant positive total effect on Attitude because of two statistically significant positive indirect effects on Attitude through the intervening variables Perceived Ease of Use and Content Feature.

2. Language Capability does not have a statistically significant positive direct effect on Attitude but it does have a positive:

(a) Statistically significant direct effect on Perceived Ease of Use

(b) Medium total effect on Attitude due to a statistically significant positive indirect effect on Attitude through the intervening variable Perceived Ease of Use. 
3. Interaction has a statistically significant positive:

(a) Direct effect on Perceived Ease of Use.

(b) Indirect effect on Attitude through the intervening variable Perceived Ease of Use.

From the new findings in Table 9 it is seen that Perceived Ease of Use plays an important mediating role in the effects of the three variables System Functionality, Language Capability, and Interaction on an individual's Attitude to BELS. Content Feature also acts as an important mediator in the indirect effect of System Functionality on an individual's Attitude to BELS.

\section{Practical Implications of the Findings}

Based on the findings of this study it is possible to propose a set of practical objectives and associated actions designed to increase an individual's positive attitude towards using BELS. For this purpose Table 10 describes a hierarchy of practical objectives and associated actions derived from the final model where for each objective the associated actions are ordered from the most effective first to the least effective last. For each action the associated model construct is identified.

Table 10: Practical objectives and actions

\begin{tabular}{|c|c|c|}
\hline Objectives & Actions & Model Construct \\
\hline \multirow{5}{*}{$\begin{array}{l}\text { Primary Objective } \\
\text { Increase a positive atti- } \\
\text { tude towards using BELS }\end{array}$} & $\begin{array}{l}\text { 1.1 Increase the interactions among students and the interac- } \\
\text { tions between students and faculty in the collaborative learn- } \\
\text { ing environment in BELS. }\end{array}$ & Interaction \\
\hline & $\begin{array}{l}\text { 1.2 Increase the perception that BELS is easy to use (see } \\
\text { Objective 2) }\end{array}$ & $\begin{array}{l}\text { Perceived Ease } \\
\text { of Use }\end{array}$ \\
\hline & $\begin{array}{l}\text { 1.3 Increase the individual's confidence in their ability to use } \\
\text { English as a learning tool in BELS. }\end{array}$ & $\begin{array}{l}\text { Language } \\
\text { Capability }\end{array}$ \\
\hline & $\begin{array}{l}\text { 1.4 Increase the perception that BELS provides flexible ac- } \\
\text { cess to instructional and assessment media. }\end{array}$ & $\begin{array}{c}\text { System } \\
\text { Functionality }\end{array}$ \\
\hline & $\begin{array}{l}\text { 1.5 Increase the perception that the presentation of content } \\
\text { and information in BELS is appropriate (see Objective 3). }\end{array}$ & Content Feature \\
\hline \multirow{3}{*}{$\begin{array}{l}\text { Objective } 2 \\
\text { Increase the perception } \\
\text { that BELS is easy to use. }\end{array}$} & $\begin{array}{l}\text { 2.1 Increase the perception that BELS provides flexible ac- } \\
\text { cess to instructional and assessment media. }\end{array}$ & $\begin{array}{c}\text { System } \\
\text { Functionality }\end{array}$ \\
\hline & $\begin{array}{l}\text { 2.2 Increase the individual's confidence in their ability to use } \\
\text { English as a learning tool in BELS. }\end{array}$ & $\begin{array}{l}\text { Language } \\
\text { Capability }\end{array}$ \\
\hline & $\begin{array}{l}\text { 2.3 Increase the interactions among students and the interac- } \\
\text { tions between students and faculty in the collaborative learn- } \\
\text { ing environment in BELS. }\end{array}$ & Interaction \\
\hline $\begin{array}{l}\text { Objective } 3 \\
\text { Increase the perception } \\
\text { that the presentation of } \\
\text { content and information } \\
\text { in BELS is appropriate. }\end{array}$ & $\begin{array}{l}\text { 3.1 Increase the perception that BELS provides flexible ac- } \\
\text { cess to instructional and assessment media. }\end{array}$ & $\begin{array}{c}\text { System } \\
\text { Functionality }\end{array}$ \\
\hline
\end{tabular}

The actions in Table 10 have been simplified so as to only include actions related to effects involving a model construct where the effect was found to be medium or large. Actions related to small effects are not included.

In relation to the actions specified in the hierarchies of actions in Table 10, it is possible to suggest practical means by which these actions may be executed and these are displayed in Table 11 . 
Table 11: Practical means associated with actions in Table 10

\begin{tabular}{|c|c|}
\hline Actions in Table 10 (Model Variable) & Suggested Means of Executing Actions \\
\hline \multirow{3}{*}{$\begin{array}{l}\text { 1. Increase the interactions among students; and the } \\
\text { interactions between students and faculty for the col- } \\
\text { laboration learning environment in BELS. } \\
\text { (Interaction) }\end{array}$} & $\begin{array}{l}\text { 1.1 BELS should provide effective interaction tools } \\
\text { such as forums, live chat. }\end{array}$ \\
\hline & $\begin{array}{l}\text { 1.2 Instructors should motivate interaction publicly } \\
\text { to increase participant communication and collabo- } \\
\text { rative learning. }\end{array}$ \\
\hline & $\begin{array}{l}\text { 1.3 Encourage instructors and learners to foster and } \\
\text { motivate the positive learning atmosphere within } \\
\text { the BELS learning context. }\end{array}$ \\
\hline \multirow{4}{*}{$\begin{array}{l}\text { 2. Increase the perceptions that the BELS is easy to } \\
\text { use. } \\
\text { (Perceived Ease of User) }\end{array}$} & 2.1 BELS's user interface should be user-friendly. \\
\hline & $\begin{array}{l}\text { 2.2 BELS's user interface should be designed sim- } \\
\text { ple and include key function to minimized user's } \\
\text { effort in learning. }\end{array}$ \\
\hline & $\begin{array}{l}\text { 2.3 BELS should be integrated the tutorials, built- } \\
\text { in help facility for assistance. }\end{array}$ \\
\hline & $\begin{array}{l}\text { 2.4 Provide the troubleshooting, helpdesk service, } \\
\text { both online and offline. }\end{array}$ \\
\hline \multirow{2}{*}{$\begin{array}{l}\text { 3. Increase the individual's confidence in their ability } \\
\text { to use English as a learning tool in BELS. } \\
\text { (Language Capability) }\end{array}$} & $\begin{array}{l}\text { 3.1 Encourage learners to have appropriate English } \\
\text { proficiency before take a blended e-learning pro- } \\
\text { gram. }\end{array}$ \\
\hline & $\begin{array}{l}\text { 3.2 BELS providers should develop the BELS us- } \\
\text { ing Vietnamese user interface. }\end{array}$ \\
\hline \multirow{3}{*}{$\begin{array}{l}\text { 4. Increase the perceptions that BELS provides flexible } \\
\text { access to instructional and assessment media. } \\
\text { (System Functionality) }\end{array}$} & $\begin{array}{l}\text { 4.1 Offer flexible access to fit various learner's } \\
\text { learning requirement. }\end{array}$ \\
\hline & $\begin{array}{l}\text { 4.2 Provide customized function to allow learners } \\
\text { control over their learning activity. }\end{array}$ \\
\hline & $\begin{array}{l}\text { 4.3 Offer various types of course content on BELS } \\
\text { (e.g. multimedia). }\end{array}$ \\
\hline \multirow{2}{*}{$\begin{array}{l}\text { 5. Increase the perceptions that the presentation of con- } \\
\text { tent and information in BELS is appropriate. } \\
\text { (Content Feature) }\end{array}$} & $\begin{array}{l}\text { 5.1 The information in BELS's course content } \\
\text { should be presented in an easy way for understand- } \\
\text { ing. }\end{array}$ \\
\hline & $\begin{array}{l}\text { 5.2 Offer good content design for related activities } \\
\text { in BELS that satisfy leaners' needs. }\end{array}$ \\
\hline
\end{tabular}

\section{Limitations of the Study}

The limitations of the study are identified in relation to the various forms of reliability and validity that apply to the measurement of variables and the overall research design.

\section{Measurement reliability and validity}

Measurement Reliability refers to the dependability or consistency of the measurement of a variable. There are 3 types of measurement reliability: stability reliability, which examines the reliability of measures across time; representative reliability, which examines the reliability of measures across different groups of subjects; and equivalence (internal consistency) reliability, which examines the internal consistency with which a set of indicators measure a latent variable (Neuman, 2006).

No statistical analyses were used to assess stability and representative reliability of measurement, and this is normally the case when a cross-sectional field study is used. However, measuring instruments used in previous studies were used and these instruments have demonstrated both of 
these forms of reliability across studies conducted at different times, in different contexts, and with different subjects.

The assessment of internal consistency (equivalence) reliability used Cronbach's Alpha coefficients for the sets of indicators for the latent variables. All of the latent variables demonstrated at least acceptable equivalence.

Measurement Validity refers to how well an empirical indicator and the conceptual definition of the construct that the indicator is supposed to measure "fit" together. There are 4 main types of measurement validity: face validity, which considers how well the measurement of an indicator "makes sense" as a measure of the construct in the judgment of others; content validity, which examines how well the measures collected represent all the aspects of the conceptual definition of the construct; criterion validity (concurrent and predictive), which examines how well the measure of the indicator agrees with a preexisting measure and how well the measure predicts future events that are logically related to the construct being measured; and construct validity (convergent and discriminant), which examines how well a set of indicators for a construct measure that and only that construct as distinct from measuring other constructs (Neumann, 2006).

In order to enhance face validity and content validity this study selected variables and relationships that were demonstrated to be important in previous studies. Established definitions of the variables were used and measuring instruments which have previously demonstrated satisfactory face and content validity were adopted. Also, a focus group was used to examine the variables included in the theoretical model, their definitions, their proposed relationships, and the questionnaire items designed to measure the variables.

Actual data from previous studies was not available and so the concurrent validity was not assessed formally using statistical methods and similarly no formal assessment was made of the predictive validity aspect of concurrent validity. However, there is evidence among the findings that the measures in the study have produced results that are in reasonable agreement with many of those reported in previous studies.

The construct validity of the measures for the latent model variables was assessed using factor analysis. As a result modifications were made to the sets of indicators for the model variables which produced a set of latent variables with satisfactory construct validity as well as some modifications to the theoretical model.

\section{Reliability and validity of the overall research design}

The Reliability of the Research Design used in the study can be tested only by repeating the study and this is strongly recommended as this is the first study of factors influencing a learner's attitude toward using BELS conducted in the context of Vietnam.

The Internal Validity of the research design assesses whether there are errors internal to the design of the study. It is used mainly in experimental research designs to examine possible errors or alternative explanations of results that arise despite attempts to institute controls (Neuman, 2006). This study was a field study using a cross-sectional approach and so the design does not allow controls to be introduced in the manner of experimental research. It is not proposed that all possible variables and causes and effects related to attitude towards using BELS were included in the proposed theoretical model. Instead, the main variables and their associated causes and effects were derived from previous studies. This means that further studies may examine other variables and causal effects which were not considered in this study and this is strongly recommended.

External Validity is used mainly in experimental research design and addresses the extent to which the findings may be generalized from a specific setting and group of subjects to other settings and groups (Neuman, 2006). This cross-sectional field study used a sample from the target 
population based on a 95 percent confidence level and a precision of 5 percent. Subject to some possible limitations listed below this sample is considered to be a satisfactory representation of individuals who were experiencing a BELS environment in Vietnam, and it is reasonable to conclude that the study has produced results similar to those that would be obtained if it was repeated.

Some possible limitations and refinements for further related studies include:

(a) The subjects were all using BELS for a course offered by the Cisco Networking Academy which related to the field of information technology. Further studies may endeavor to consider the use of BELS in relation to other fields of study where, for example, constructs such as Computer Self-efficacy and Perceived Ease of Use may play different roles.

(b) Most of the subjects (87 percent) were males, 66 percent had previous experience with BELS, 91 percent were of age 18-27 years, and nearly 90 percent held a diploma or a bachelor degree.

Further studies may vary these characteristics of the subjects.

Statistical Validity refers to the appropriate use of statistical techniques (Neuman, 2006). Descriptive statistics were used and addressed: missing values, outliers, skewness, kurtosis, means, standard deviations, factor analysis, Cronbach's alpha coefficients, t-tests, and correlation coefficients. Model development used structural equation modeling with maximum likelihood estimation implemented with AMOS software to test the modified theoretical model and to develop that model in order to arrive at a final model. All of the statistical techniques were used appropriately in accordance with requirements and specified conditions.

\section{Conclusion}

From a theoretical perspective 17 hypotheses derived from previous studies were examined and there was full or partial support for 13 of these hypotheses. In particular, the findings strengthen the evidence for the importance of the positive effects of content features and interaction among students and teachers on developing a positive attitude toward BELS. Also, the well-known relationship between ease of use and attitude in the TAM was confirmed. New findings (Table 9) included the effects of three factors (the functionality of BELS, the English language capability of individuals, and the interaction between students and teachers) on an individual's attitude to BELS and the ease of using BELS, which was found to be an important mediator in effects on attitude. It is strongly recommended that these new findings as well the four hypotheses that were not supported, which involved effects due to three personality traits (Openness, Extraversion, and Neuroticism), be examined again in future studies.

From a practical perspective the study provide useful insights for educational institutions wishing to adopt BELS to combine e-learning with traditional classroom instruction. Better decisions in the design and use of BELS can be made by considering the practical objects and actions presented in Table 10. In particular, increasing interactions among students and teachers in the BELS environment (e.g., using interaction tools such as forums and live chat) was found to be the most effective way to improve a student's attitude to BELS. Also, BELS must be easy to use and the user interface must be simple, friendly, and include functions to minimize a user's effort in learning. There should be integrated tutorials, built-in help and troubleshooting facilities, and helpdesk services, both online and offline. Because of the important effect of English language capability in this study BELS learners should be encouraged to have appropriate English proficiency or alternatively providers should develop BELS using a Vietnamese user interface. BELS should provide flexible access to a diversity of learning materials and content. Students should be able to customized function the way they use BELS in order to allow them to have control over their learning activities. 
As this is the first study of this type to be conducted in the context of Vietnam it is strongly recommended that the study be repeated in order to establish the external validity of the results. As described above, future studies should address the limitations of this study and further examine the hypotheses not supported by the findings as well as the new findings.

\section{References}

Agarwal, R., \& Prasad, J. (1999). Are individual differences germane to the acceptance of new information technologies? Decision Sciences, 30(2), 361-391.

Al-Huwail, N., Al-Sharhan, S., \& Al-Hunaiyyan, A. (2007). Learning design for a successful blended elearning environment: Cultural dimensions. INFOCOMP Journal of Computer Science, 6(4), 60-69.

Ambient Insight. (2014, September). Ambient Insight Regional Report: The 2013-2018 Asia Self-paced eLearning Market. Ambient Insight.

Anh, H. S. (2012). E-learning for Vietnam high school student (E-learning đối với học sinh phổ thông Việt Nam). Retrieved December 5, 2014, from http://chuyenquangtrung.edu.vn/bai-viet-ve-khoa-hoc-giao$\underline{\text { duc }}$

BaoMoi.com. (2014). MOET and Viettel Corporation signed a cooperation agreement on comprehensive IT and telecommunicationss(Bộ GD\&DT và Tập đoàn Viettel ký thỏa thuận hợp tác toàn diện về CNTT và viễn thông). Retrieved December 5, 2014, from http://www.baomoi.com/Bo-GDDT-va-Tapdoan-Viettel-ky-thoa-thuan-hop-tac-toan-dien-ve-CNTT-va-vien-thong/59/13926258.epi

Barrick, M. R., Mount, M. K., \& Judge, T. A. (2001). Personality and performance at the beginning of the new millennium: What do we know and where do we go next? International Journal of Selection and Assessment, 9(1-2), 9-30.

Burger, J. M. (2008). Personality (7th ed.). Thomson Wadsworth, Belmont.

Cheng, Y.-M. (2011). Antecedents and consequences of e-learning acceptance. Information Systems Journal, 21(3), 269-299.

Chih-Min Ma, C.-M. C., \& Cheng, B.-W. (2013). Integrating technology acceptance model and tasktechnology fit into blended e-learning system. Journal of Applied Sciences, 13, 736-742.

Chou, S.-W., \& Liu, C.-H. (2005). Learning effectiveness in a Web-based virtual learning environment: A learner control perspective. Journal of Computer Assisted Learning, 21(1), 65-76.

Cohen, J. (1988). Statistical power analysis for the behavioral sciences (2nd ed.). Academic Press, New York.

Cohen, J., \& Cohen, P. (1983). Applied multiple regression/correlation analysis for the behavioral sciences (3rd ed.). Mahwah, NJ, Erlbaum.

Compeau, D. R., \& Higgins, C. A. (1995). Computer self-efficacy: Development of a measure and initial test. MIS Quarterly, 189-211.

Costa, P. T., \& McCrae, R. R. (1992). Revised NEO Personality Inventory (NEO PI-R) and NEO FiveFactor Inventory (NEO-FFI) professional manual. Psychological Assessment Resources Odessa, FL.

Davis, F. D. (1985). A technology acceptance model for empirically testing new end-user information systems: Theory and results. (Doctoral dissertation). Massachusetts Institute of Technology. Retrieved from http://dspace.mit.edu/handle/1721.1/15192

Davis, F. D., Bagozzi, R. P., \& Warshaw, P. R. (1989). User acceptance of computer technology: A comparison of two theoretical models. Management Science, 35(8), 982-1003.

Dennis, A., Bichelmeyer, B., Henry, D., Cakir, H., Korkmaz, A., Watson, C., \& Bunnage, J. (2006). The Cisco networking academy: A model for the study of student success in a blended learning 
environment. In C. J. Bonk \& C. R. Graham (Eds.), The handbook of blended learning: Global perspectives, local designs (pp. 120-135). San Francisco: Pfeiffer.

Devaraj, S., Easley, R. F., \& Crant, J. M. (2008). Research note-how does personality matter? Relating the five-factor model to technology acceptance and use. Information Systems Research, 19(1), 93-105.

Donnellan, M. B., Oswald, F. L., Baird, B. M., \& Lucas, R. E. (2006). The mini-IPIP scales: Tiny-yeteffective measures of the Big Five factors of personality. Psychological Assessment, 18(2), 192.

Ferriman, N. (2013). The impact of blended e-learning on undergraduate academic essay writing in English (L2). Computers \& Education, 60(1), 243-253.

Garrison, D. R. (2011). E-learning in the 21st century: A framework for research and practice. Taylor \& Francis.

George, D., \& Mallery, P. (2003). SPSS for Windows step by step: A simple guide and reference. 11.0 update. Boston: Allyn and Bacon.

Gong, M., Xu, Y., \& Yu, Y. (2004). An enhanced technology acceptance model for web-based learning. Journal of Information Systems Education, 15(4), 365-374.

Graham, C. R. (2006). Chapter 1:Blended learning systems: Definition, current trends, future directions. In C. J. Bonk \& C. R. Graham (Eds.), The handbook of blended learning: Global perspectives, local designs (pp. 3-19). San Francisco: Pfeiffer.

Hong, W., Thong, J. Y., Wong, W.-M., \& Tam, K. Y. (2002). Determinants of user acceptance of digital libraries: An empirical examination of individual differences and system characteristics. Journal of Management Information Systems, 18(3), 97-124.

Hsieh, L.-Y., Lu, Y.-J., \& Lee, Y.-H. (2014). Using the technology acceptance model to explore the behavioral intentions toward blended learning. In D. Liberona \& L. Uden (Eds.), Learning technology for education in cloud. MOOC and big data (pp. 195-203). Springer.

Huynh, Q. L., \& Le Thi, T. L. (2014). The mediating role of the perceived usefulness in the acceptance of e-learning. International Journal of Humanities and Social Science Invention.

Israel, G. D. (2013, June). Determining sample size. Retrieved December 20, 2014, from https://edis.ifas.ufl.edu/pd006

Jeffrey, L. M., Milne, J., Suddaby, G., \& Higgins, A. (2014). Blended learning: How teachers balance the blend of online and classroom components. Journal of Information Technology Education: Research, 13, 121-140. Retrieved from http://www.informingscience.org/Publications/1968

Kline, R. B. (2005). Principles and practice of structural equation modeling. London: Guilford Press.

López-Pérez, M. V., Pérez-López, M. C., \& Rodrıguez-Ariza, L. (2011). Blended learning in higher education: Students' perceptions and their relation to outcomes. Computers \& Education, 56(3), 818826.

Migliore, L. A. (2011). Relation between big five personality traits and Hofstede's cultural dimensions: Samples from the USA and India. Cross Cultural Management: An International Journal, 18(1), 3854.

Mukkavilli, S. (2008). E-learning for evaluation capacity development. Surry, UK.

Neuman, W. L. (2006). Social research methods: Qualitative and quantitative approaches. Boston: Allyn and Bacon.

Nguyen, T. D., Nguyen, D. T., \& Cao, T. H. (2014). Acceptance and use of information system: E-learning based on cloud computing in Vietnam. Information and Communication Technology. Proceedings of the Second IFIP TC5/8 International Conference, ICT-EurAsia 2014, Bali, Indonesia. 139-149. Springer.

Park, S. Y. (2009). An analysis of the technology acceptance model in understanding university students' behavioral intention to use e-learning. Educational Technology \& Society, 12(3), 150-162. 
Pervin, L. A., Cervone, D., \& John, O. P. (2008). Personality theory and research (10th ed.). New Jersey: John Wiley \& Sons.

Pituch, K. A., \& Lee, Y. (2006). The influence of system characteristics on e-learning use. Computers \& Education, 47(2), 222-244.

Porter, W. W., Graham, C. R., Spring, K. A., \& Welch, K. R. (2014). Blended learning in higher education: Institutional adoption and implementation. Computers \& Education, 75, 185-195.

Prieto, I. M., \& Revilla, E. (2006). Formal and informal facilitators of learning capability: The moderating effect of learning climate. Instituto de Empresa.

Punnoose, A. (2012). Determinants of intention to use elearning based on the technology acceptance model. Journal of Information Technology Education: Research, 11(1), 301-337. Retrieved from http://www.informingscience.org/Publications/1744

Ryckman, R. (2008). Theories of personality (9th ed.). Belmon: Thomson Wadsworth t.

Saadé, R., Nebebe, F., \& Tan, W. (2007). Viability of the“ technology acceptance model" in multimedia learning environments: a comparative study. Interdisciplinary Journal of E-Learning and Learning Objects, 3, 175-184. Retrieved from http://www.informingscience.org/Publications/392

Sánchez, R. A., \& Hueros, A. D. (2010). Motivational factors that influence the acceptance of Moodle using TAM. Computers in Human Behavior, 26(6), 1632-1640.

Sorden, S. D., \& Munene, I. I. (2013). Constructs related to community college student satisfaction in blended learning. Journal of Information Technology Education: Research, 12, 251-270. Retrieved from http://www.informingscience.org/Publications/1890

Straub, D., Boudreau, M.-C., \& Gefen, D. (2004). Validation guidelines for IS positivist research. The Communications of the Association for Information Systems, 13(1), 63.

Svendsen, G. B., Johnsen, J.-A. K., Almås-Sørensen, L., \& Vittersø, J. (2013). Personality and technology acceptance: The influence of personality factors on the core constructs of the Technology Acceptance Model. Behaviour \& Information Technology, 32(4), 323-334.

Tsai, S., \& Machado, P. (2002). E-Learning basics: Essay. Elearn magazine, 2002(7), 3. Retrieved December 7, 2014, from http://elearnmag.acm.org/archive.cfm?aid=568597

Tselios, N. K., Daskalakis, S., \& Papadopoulou, M. (2011). Assessing the acceptance of a blended learning university course. Educational Technology \& Society, 14(2), 224-235.

Venkatesh, V., \& Davis, F. D. (2000). A theoretical extension of the technology acceptance model: Four longitudinal field studies. Management Science, 46(2), 186-204.

Vu, C. T. M., Nguyen, V. Q., \& Lin, C.-C. (2011). Student e-learning acceptance of join academic graduate programs in a developing country. Global Learn, 2011, 938-948.

Wixom, B. H., \& Todd, P. A. (2005). A theoretical integration of user satisfaction and technology acceptance. Information Systems Research, 16(1), 85-102.

Wu, J.-H., Hsia, T.-L., Liao, Y.-W., \& Tennyson, R. (2008). What determinates student learning satisfaction in a blended e-learning system environment? PACIS 2008 Proceedings, 149.

Wu, J.-H., Tennyson, R. D., \& Hsia, T.-L. (2010). A study of student satisfaction in a blended e-learning system environment. Computers \& Education, 55(1), 155-164.

Yang, Y.-T. C., Chuang, Y.-C., Li, L.-Y., \& Tseng, S.-S. (2013). A blended learning environment for individualized English listening and speaking integrating critical thinking. Computers \& Education, $63,285-305$.

Yang, Z., \& Liu, Q. (2007). Research and development of web-based virtual online classroom. Computers \& education, 48(2), 171-184. 
Zhang, X., Keeling, K. B., \& Pavur, R. J. (2000). Information quality of commericial web site home pages: An explorative analysis. Proceedings of The Twenty first International Conference on Information Systems (pp. 164-175). Association for Information Systems.

Žuvi-Butorac, M., Roncevi, N., Nemcanin, D., \& Nebi, Z. (2011). Blended e-learning in higher education: Research on students' perspective. Issues in Informing Science and Information Technology, 8, 409429.

\section{Appendix}

\section{Notated Questionnaire}

\section{Section 1}

1. Your gender?(G) $\square$ Male (1) $\quad \square$ Female (2)

2. What is your age range in years? (A) $\square$ 18-22 (20)

23-27(25) $\square 28-32(\mathbf{3 0})$
$\square$ 33-37 (35)
$\square 38$ or more (40)

3. What is your highest level of education? (E) $\square$ High school or equivalent (12)

Diploma (14)
$\square$ Bachelor Degree (16)
$\square$ Post-graduate (19)

4. Is this the first time that you have undertaken a training program that combines traditional face-to-face instruction and the using of an e-learning system? (EXP) $\square$ Yes (1) $\quad \square$ No (2)

\section{Section 2}

Participants responded to the given statements using the 5-point Likert scale: (1) Strongly Disagree, (2) Disagree, (3) Neutral, (4) Agree, (5) Strongly Agree.

\begin{tabular}{|c|c|c|c|c|c|}
\hline \begin{tabular}{|l|}
\multicolumn{1}{|c|}{ Computer } \\
$\quad$ Self-efficacy \\
I could use BELS for \\
learning:
\end{tabular} & Indicator & $\begin{array}{c}\text { System } \\
\text { Functionality }\end{array}$ & Indicator & $\begin{array}{l}\text { Content } \\
\text { Feature }\end{array}$ & Indicator \\
\hline $\begin{array}{l}\text { If there was no one } \\
\text { around to tell me } \\
\text { what to do as I go. }\end{array}$ & CSE1 & $\begin{array}{l}\text { BELS allows learners to } \\
\text { have control over their } \\
\text { learning activity. }\end{array}$ & SF1 & $\begin{array}{l}\text { The content of BELS is } \\
\text { personalized. }\end{array}$ & CF1 \\
\hline $\begin{array}{l}\text { If I had never used a } \\
\text { package like it be- } \\
\text { fore. }\end{array}$ & CSE2 & $\begin{array}{l}\text { BELS offers flexibility in } \\
\text { the time and place for } \\
\text { learning. }\end{array}$ & SF2 & $\begin{array}{l}\text { The presentation method } \\
\text { of content in BELS is easy } \\
\text { for understanding. }\end{array}$ & CF2 \\
\hline $\begin{array}{l}\text { If I had just the } \\
\text { built-in help facility } \\
\text { for assistance. }\end{array}$ & CSE3 & $\begin{array}{l}\text { BELS offers various types } \\
\text { of course content (e.g. } \\
\text { audio, video, and text). }\end{array}$ & SF3 & $\begin{array}{l}\text { The design method for } \\
\text { related activities in BELS } \\
\text { is suitable and appropriate. }\end{array}$ & CF3 \\
\hline \multicolumn{2}{|c|}{ Language Capability } & \multicolumn{2}{|l|}{ Interaction } & \multicolumn{2}{|l|}{ Learning Climate } \\
\hline $\begin{array}{l}\text { I feel confident us- } \\
\text { ing English in } \\
\text { BELS. }\end{array}$ & LAC1 & $\begin{array}{l}\text { BELS enables interactive } \\
\text { communication between } \\
\text { instructor and students. }\end{array}$ & I1 & $\begin{array}{l}\text { The course using BELS is } \\
\text { interesting. }\end{array}$ & $\mathrm{LC} 1$ \\
\hline $\begin{array}{l}\text { I think English in } \\
\text { BELS is easy to } \\
\text { understand. }\end{array}$ & LAC2 & $\begin{array}{l}\text { BELS enables interactive } \\
\text { communication among } \\
\text { students. }\end{array}$ & $\mathrm{I} 2$ & $\begin{array}{l}\text { I felt less pressure in the } \\
\text { BELS learning environ- } \\
\text { ment. }\end{array}$ & $\mathrm{LC} 2$ \\
\hline \multirow[t]{2}{*}{$\begin{array}{l}\text { Overall, English in } \\
\text { not an obstacle to } \\
\text { learning in BELS. }\end{array}$} & LAC3 & $\begin{array}{l}\text { BELS environment is } \\
\text { excellent for social inter- } \\
\text { action. }\end{array}$ & I3 & $\begin{array}{l}\text { The climate in the BELS } \\
\text { learning environment helps } \\
\text { me to learn. }\end{array}$ & LC3 \\
\hline & & & & $\begin{array}{l}\text { The interaction feature in } \\
\text { BELS helps me to learn }\end{array}$ & LC4 \\
\hline
\end{tabular}




\begin{tabular}{|l|c|l|l|l|c|}
\hline \multicolumn{2}{|c|}{ Perceive Ease of Use } & \multicolumn{1}{c|}{ Perceive Usefulness } & \multicolumn{2}{c|}{ Attitude } \\
\hline $\begin{array}{l}\text { I find BELS easy to } \\
\text { use. }\end{array}$ & PE1 & $\begin{array}{l}\text { BELS improves my learn- } \\
\text { ing performance. }\end{array}$ & PU1 & $\begin{array}{l}\text { Studying with BELS is a } \\
\text { good idea. }\end{array}$ & AT1 \\
\hline $\begin{array}{l}\text { Learning how to use } \\
\text { BELS is easy for } \\
\text { me. }\end{array}$ & PE2 & $\begin{array}{l}\text { BELS increases academic } \\
\text { productivity. }\end{array}$ & $\begin{array}{l}\text { Studying using BELS is a } \\
\text { wise idea. }\end{array}$ & AT2 \\
\hline $\begin{array}{l}\text { It is easy to become } \\
\text { skillful at using }\end{array}$ & PE3 & $\begin{array}{l}\text { BELS makes it easier to } \\
\text { study course content. }\end{array}$ & PU3 & $\begin{array}{l}\text { I am positive toward using } \\
\text { BELS. }\end{array}$ & AT3 \\
\hline
\end{tabular}

\section{Personality Traits}

Respondents indicated their responses on the 5-point Likert scale: (1) Very Inaccurate, (2) Moderately Inaccurate, (3) Neither Inaccurate nor Accurate, (4) Moderately Accurate, (5) Very Accurate

\begin{tabular}{|l|c|l|c|}
\hline I believe that I: & Indicator & & Indicator \\
\hline Am the life of the party. & $\mathrm{EX} 1$ & Like order. & $\mathrm{CO} 3$ \\
\hline Don't talk a lot. & $\mathrm{EX} 2$ & Make a mess of things. & $\mathrm{CO} 4$ \\
\hline Talk to a lot of different people at parties. & $\mathrm{EX} 3$ & Have frequent mood swings. & NE1 \\
\hline Keep in the background. & $\mathrm{EX} 4$ & Am relaxed most of the time. & NE2 \\
\hline Sympathize with others' feelings. & $\mathrm{AG} 1$ & Get upset easily. & NE3 \\
\hline Am not interested in other people's problems. & $\mathrm{AG} 2$ & Seldom feel blue. & NE4 \\
\hline Feel others' emotions. & $\mathrm{AG} 3$ & Have a vivid imagination. & OE1 \\
\hline Am not really interested in others. & $\mathrm{AG} 4$ & Am not interested in abstract ideas. & OE2 \\
\hline Get chores done right away. & $\mathrm{CO} 1$ & $\begin{array}{l}\text { Have difficulty understanding abstract } \\
\text { ideas. }\end{array}$ & OE3 \\
\hline $\begin{array}{l}\text { Often forget to put things back in their proper } \\
\text { place. }\end{array}$ & $\mathrm{CO} 2$ & Do not have a good imagination. & OE4 \\
\hline Note: Highlighted questions are reverse scored. & & \\
\hline
\end{tabular}

Table A1: Final Factor Analysis

\begin{tabular}{|c|c|c|c|c|c|c|c|c|c|c|c|c|}
\hline \multirow[b]{2}{*}{ Indicator } & \multicolumn{12}{|c|}{ Latent Variable } \\
\hline & $\mathrm{OE}$ & EX & $\mathrm{NE}$ & $\begin{array}{c}\text { I } \\
\text { and LC }\end{array}$ & $\begin{array}{l}\text { PU and } \\
\text { AT }\end{array}$ & $\mathrm{CO}$ & AG & PE & LAC & SF & $\mathrm{CF}$ & CSE \\
\hline CSE1 & -.074 & .014 & -.007 & .033 & .048 & .019 & -.027 & .114 & .108 & .127 & .132 & .825 \\
\hline CSE2 & -.104 & .003 & .034 & .075 & .093 & .068 & -.021 & .093 & .104 & .126 & .113 & .852 \\
\hline CSE3 & .001 & -.008 & .106 & .061 & .091 & .011 & .091 & .031 & .106 & .128 & .033 & .844 \\
\hline SF1 & .018 & .030 & .020 & .121 & .127 & .067 & .110 & .133 & .069 & .740 & .189 & .202 \\
\hline SF2 & .062 & .013 & .067 & .131 & .119 & .047 & .058 & .186 & .082 & .831 & .091 & .155 \\
\hline SF3 & .099 & -.005 & .008 & .104 & .105 & .035 & .081 & .117 & .070 & .835 & .153 & .130 \\
\hline CF1 & .002 & .076 & -.002 & .130 & -.082 & .101 & -.020 & .085 & .123 & .223 & .725 & .129 \\
\hline CF2 & .103 & .045 & .028 & .117 & .203 & .037 & .036 & .085 & .174 & .095 & .779 & .181 \\
\hline CF3 & .066 & .022 & -.001 & .086 & .245 & .104 & .023 & .045 & .147 & .131 & .766 & .058 \\
\hline LAC1 & .008 & .043 & -.010 & .070 & .080 & .019 & .035 & .109 & .886 & .067 & .109 & .142 \\
\hline LAC2 & .065 & -.035 & -.010 & .092 & .162 & .119 & -.022 & .178 & .834 & .035 & .124 & .144 \\
\hline LAC3 & -.065 & -.016 & -.010 & .030 & .079 & .064 & .060 & .101 & .862 & .080 & .136 & .061 \\
\hline I1 & .040 & .033 & .001 & .806 & .165 & .042 & .012 & .045 & .114 & .162 & .103 & .115 \\
\hline 12 & .045 & .094 & -.049 & .826 & .159 & .058 & .079 & .003 & .102 & .085 & .098 & .137 \\
\hline I3 & -.037 & .095 & -.058 & .762 & .156 & .009 & .001 & .056 & .053 & .237 & .150 & .045 \\
\hline $\mathrm{LC} 1$ & -.018 & -.041 & -.073 & .519 & .253 & -.038 & .175 & .228 & .102 & .116 & .339 & .102 \\
\hline LC2 & -.006 & -.033 & -.052 & .422 & .207 & -.038 & .204 & .338 & .150 & .195 & .334 & .040 \\
\hline LC3 & .017 & .051 & -.021 & .534 & .297 & -.055 & .132 & .313 & .115 & .153 & .286 & .028 \\
\hline LC4 & .082 & .041 & -.004 & .491 & .272 & .003 & .169 & .372 & .085 & .156 & .335 & .070 \\
\hline PE1 & $\begin{array}{l}.002 \\
\end{array}$ & .032 & 014 & .067 & .296 & 084 & 023 & 710 & .208 & .221 & .035 & .126 \\
\hline
\end{tabular}




\begin{tabular}{|c|c|c|c|c|c|c|c|c|c|c|c|c|}
\hline PE2 & .038 & .091 & -.029 & .020 & .159 & .080 & .078 & .837 & .151 & .146 & .079 & .112 \\
\hline PE3 & .046 & .075 & .028 & .058 & .135 & -.009 & .022 & .833 & .148 & .140 & .115 & .107 \\
\hline PU1 & -.016 & .012 & .019 & .201 & .762 & .053 & .037 & .234 & .137 & .113 & .133 & .181 \\
\hline PU2 & .000 & .025 & .013 & .204 & .765 & .041 & .063 & .225 & .220 & .085 & .121 & .133 \\
\hline PU3 & .030 & .044 & -.060 & .134 & .704 & .038 & .048 & .176 & .283 & .133 & .170 & .150 \\
\hline AT2 & -.004 & -.044 & -.076 & .228 & .588 & .050 & .049 & .240 & .013 & .308 & .205 & .055 \\
\hline AT3 & -.001 & -.010 & -.034 & .207 & .586 & .052 & .028 & .254 & .093 & .355 & .206 & .061 \\
\hline EX1 & -.044 & .917 & -.019 & .028 & .015 & .037 & .117 & .046 & .005 & .010 & .041 & .022 \\
\hline EX2 & .068 & .917 & -.048 & .039 & -.024 & -.023 & .093 & .021 & -.010 & .047 & .026 & .018 \\
\hline EX3 & .003 & .893 & -.048 & .032 & .026 & .050 & .093 & .072 & .027 & -.006 & .026 & .009 \\
\hline EX4 & .019 & .916 & -.057 & .061 & .009 & -.047 & .042 & .045 & -.011 & -.005 & .040 & -.023 \\
\hline AG1 & .086 & .095 & -.004 & .052 & .036 & .202 & .810 & .069 & .031 & .021 & -.028 & .129 \\
\hline AG2 & .136 & .068 & -.125 & -.011 & -.022 & .166 & .800 & .053 & .031 & .097 & .061 & -.041 \\
\hline AG3 & .038 & .108 & -.043 & .097 & .082 & .188 & .756 & .128 & .017 & .061 & .008 & .065 \\
\hline AG4 & .115 & .100 & -.106 & .069 & .042 & .122 & .816 & -.056 & .046 & .109 & .083 & -.070 \\
\hline $\mathrm{CO} 1$ & .022 & .007 & -.114 & .013 & .029 & .792 & .103 & .078 & .098 & .037 & .016 & .073 \\
\hline $\mathrm{CO} 2$ & .074 & -.009 & -.088 & .000 & -.048 & .821 & .138 & .034 & .106 & .040 & .118 & .002 \\
\hline $\mathrm{CO} 3$ & .054 & .001 & .010 & -.040 & .077 & .851 & .175 & .059 & -.006 & .062 & .009 & .047 \\
\hline $\mathrm{CO} 4$ & .130 & .016 & -.148 & .067 & .072 & .798 & .237 & -.058 & .039 & .030 & .092 & .006 \\
\hline NE1 & -.105 & .000 & .883 & -.067 & -.004 & -.047 & -.088 & .027 & .016 & -.012 & .033 & .023 \\
\hline NE2 & -.046 & -.055 & .887 & -.014 & -.041 & -.088 & -.059 & -.030 & -.051 & .030 & -.045 & .065 \\
\hline NE3 & -.093 & -.095 & .888 & .009 & -.034 & -.100 & -.092 & .043 & -.019 & -.002 & -.018 & .046 \\
\hline NE4 & -.104 & -.026 & .890 & -.039 & .011 & -.091 & -.023 & -.047 & .009 & .051 & .023 & .022 \\
\hline OE1 & .871 & .057 & -.050 & .009 & .033 & .158 & .076 & .065 & .022 & .053 & .054 & -.018 \\
\hline OE2 & .907 & -.008 & -.102 & -.048 & .020 & .041 & .102 & .003 & -.024 & .055 & .015 & -.060 \\
\hline OE3 & .918 & -.005 & -.119 & .041 & -.028 & .007 & .065 & .019 & .024 & .022 & .030 & -.032 \\
\hline OE4 & .918 & .004 & -.085 & .045 & -.018 & .072 & .117 & .011 & -.011 & .054 & .071 & -.088 \\
\hline & & & & & I Var & $\mathbf{E x}$ & ined & & & & & \\
\hline & & & Initic & Eigenv & & & & Rotati & Sums o & quare & Loadin & \\
\hline $\begin{array}{c}\text { Latent } \\
\text { Variable }\end{array}$ & & & $\begin{array}{r}\text { Percentag } \\
\text { anc }\end{array}$ & of vari- & $\begin{array}{l}\text { Cun } \\
\text { Per }\end{array}$ & $\begin{array}{l}\text { lative } \\
\text { ntage }\end{array}$ & & $\mathrm{Pe}$ & $\begin{array}{l}\text { entage of } \\
\text { ance }\end{array}$ & & $\begin{array}{l}\text { Cumul } \\
\text { Percen }\end{array}$ & \\
\hline $\mathrm{OE}$ & & & 22.3 & & & 304 & & & 7.323 & & 7.32 & \\
\hline EX & & & 10.7 & & & 052 & & & 7.296 & & 14.6 & \\
\hline $\mathrm{NE}$ & & & 7.18 & & & 241 & & & 7.032 & & 21.6 & \\
\hline I and LC & & & 6.0 & & & 339 & & & 6.887 & & 28.5 & \\
\hline PU and AT & & & 5.8 & & & 188 & & & 6.528 & & 35.0 & \\
\hline $\mathrm{CO}$ & & & 4.72 & & & 912 & & & 6.249 & & 41.3 & \\
\hline $\mathrm{AG}$ & & & 3.9 & & & 856 & & & 6.209 & & 47.5 & \\
\hline $\mathrm{PE}$ & & & 3.7 & & & 628 & & & 5.925 & & 53.4 & \\
\hline LAC & & & 3.4 & & & 032 & & & 5.740 & & 59.1 & \\
\hline SF & & & 2.8 & & & 931 & & & 5.654 & & 64.8 & \\
\hline $\mathrm{CF}$ & & & 2.4 & & & 400 & & & 5.415 & & 70.2 & \\
\hline CSE & & & 2.2 & & & 632 & & & 5.374 & & 75.6 & \\
\hline
\end{tabular}

Notes: (a) Extraction Method: Principal Component Analysis; (b) Rotation Method: Equamax with Kaiser Normalization. Rotation converged in 10 iterations; (c) Kaiser-Meyer-Olkin Measure of Sampling Adequacy = .878; (d) Bartlett's Test of Sphericity Approx: Chi-Square 12681.506, $\mathrm{df}=1081, \mathrm{p}=0.000$; (e) Significant loading factors are highlighted; (f) Only latent variables with eigenvalues $\geq 1$ are shown.

Table A2: Cronbach alpha coefficients

\begin{tabular}{|l|c|c|l|c|c|c|c|c|}
\hline $\begin{array}{c}\text { Latent } \\
\text { Variable }\end{array}$ & Alpha & Interpretation & $\begin{array}{c}\text { Latent } \\
\text { Variable }\end{array}$ & Alpha & Interpretation & $\begin{array}{c}\text { Latent } \\
\text { Variable }\end{array}$ & Alpha & Interpretation \\
\hline OE & 0.939 & Excellent & AT & 0.876 & Good & LAC & 0.887 & Good \\
\hline EX & 0.939 & Excellent & CO & 0.871 & Good & SF & 0.854 & Good \\
\hline NE & 0.992 & Excellent & AG & 0.860 & Good & CF & 0.790 & Acceptable \\
\hline I & 0.885 & Good & PE & 0.868 & Good & CSE & 0.852 & Good \\
\hline
\end{tabular}


Table A3: Descriptive statistics for model variables

\begin{tabular}{|c|c|c|c|c|c|c|c|c|c|}
\hline $\begin{array}{l}\text { Variable/ } \\
\text { Indicator }\end{array}$ & Mean & $\begin{array}{l}\text { Standard } \\
\text { Deviation }\end{array}$ & Skewness & Kurtosis & $\begin{array}{l}\text { Variable/ } \\
\text { Indicator }\end{array}$ & Mean & $\begin{array}{l}\text { Standard } \\
\text { Deviation }\end{array}$ & Skewness & Kurtosis \\
\hline $\begin{array}{l}\text { Computer } \\
\text { Self-efficacy }\end{array}$ & 3.40 & .725 & -.275 & .331 & PU2 & 3.67 & .689 & .019 & -.285 \\
\hline CSE1 & 3.43 & .865 & -.422 & .086 & PU3 & 3.74 & .665 & -.010 & -.256 \\
\hline CSE2 & 3.32 & .831 & -.132 & -.254 & AT2 & 3.80 & .685 & .087 & -.534 \\
\hline CSE3 & 3.43 & .778 & -.193 & -.144 & AT3 & 3.94 & .703 & -.043 & -.641 \\
\hline $\begin{array}{l}\text { System } \\
\text { Functionality }\end{array}$ & 4.10 & .582 & -.361 & .100 & Extraversion & 3.46 & .915 & -.426 & -.280 \\
\hline SF1 & 3.95 & .645 & -.241 & .222 & EX1 & 3.72 & .985 & -.641 & .247 \\
\hline SF2 & 4.15 & .659 & -.272 & -.300 & EX2 & 3.34 & 1.044 & -.089 & -.598 \\
\hline SF3 & 4.19 & .680 & -.352 & -.453 & EX3 & 3.51 & .985 & -.350 & -.416 \\
\hline $\begin{array}{l}\text { Content Fea- } \\
\text { ture }\end{array}$ & 3.66 & .599 & -.002 & .230 & EX4 & 3.29 & .966 & -.293 & -.260 \\
\hline CF1 & 3.60 & .745 & -.091 & -.285 & Agreeableness & 3.92 & .642 & -.238 & -.507 \\
\hline CF2 & 3.68 & .715 & -.115 & -.207 & $\mathrm{AG} 1$ & 4.06 & .779 & -.498 & -.206 \\
\hline CF3 & 3.69 & .680 & -.112 & -.136 & AG2 & 3.85 & .806 & -.038 & -.850 \\
\hline $\begin{array}{l}\text { Language } \\
\text { Capability }\end{array}$ & 3.36 & .739 & -.112 & .439 & AG3 & 3.87 & .709 & -.196 & -.181 \\
\hline LAC1 & 3.35 & .809 & .000 & .022 & AG4 & 3.91 & .763 & -.090 & -.742 \\
\hline LAC2 & 3.40 & .784 & -.129 & .468 & Conscientiousness & 3.85 & .674 & -.239 & -.710 \\
\hline LAC3 & 3.34 & .861 & -.233 & -.125 & $\mathrm{CO} 1$ & 3.77 & .747 & -.069 & -.428 \\
\hline Interaction & 3.73 & .533 & .094 & -.017 & $\mathrm{CO} 2$ & 3.73 & .791 & -.201 & -.375 \\
\hline I1 & 3.70 & .718 & -.425 & .125 & $\mathrm{CO} 3$ & 3.97 & .798 & -.246 & -.713 \\
\hline $\mathrm{I} 2$ & 3.67 & .731 & -.337 & -.036 & $\mathrm{CO} 4$ & 3.94 & .837 & -.250 & -.789 \\
\hline $\mathrm{I} 3$ & 3.68 & .741 & -.154 & -.236 & Neuroticism & 2.89 & .884 & -.153 & -.605 \\
\hline $\mathrm{LC} 1$ & 3.69 & .672 & -.046 & -.200 & NE1 & 2.94 & 1.020 & -.147 & -.611 \\
\hline $\mathrm{LC} 2$ & 3.76 & .707 & .029 & -.439 & NE2 & 2.83 & .948 & -.112 & -.541 \\
\hline LC3 & 3.77 & .651 & .100 & -.438 & NE3 & 2.86 & 1.022 & -.123 & -.613 \\
\hline $\mathrm{LC} 4$ & 3.83 & .626 & -.048 & -.139 & NE4 & 2.94 & .935 & -.089 & -.172 \\
\hline $\begin{array}{l}\text { Perceived } \\
\text { Ease of Use }\end{array}$ & 3.712 & .627 & -.031 & .040 & $\begin{array}{l}\text { Openness to Ex- } \\
\text { perience }\end{array}$ & 3.50 & .898 & -.443 & -.082 \\
\hline PE1 & 3.75 & .689 & -.284 & .086 & OE1 & 3.63 & .891 & -.225 & -.371 \\
\hline PE2 & 3.76 & .699 & -.121 & -.184 & OE2 & 3.43 & 1.025 & -.319 & -.230 \\
\hline PE3 & 3.63 & .727 & .071 & -.359 & OE3 & 3.36 & .957 & -.382 & .103 \\
\hline Attitude & 3.76 & .558 & .148 & -.170 & OE4 & 3.59 & 1.029 & -.415 & -.357 \\
\hline PU1 & 3.67 & .671 & .006 & -.247 & & & & & \\
\hline
\end{tabular}

Table A4: Correlations

\begin{tabular}{|c|c|c|c|c|c|c|c|c|c|c|c|}
\hline Variable & CSE & SF & $\mathrm{CF}$ & LAC & I & PE & AT & $\mathrm{EX}$ & $\mathrm{AG}$ & $\mathrm{CO}$ & $\mathrm{NE}$ \\
\hline Computer Self-efficacy (CSE) & 1 & & & & & & & & & & \\
\hline System Functionality (SF) & .363 & 1 & & & & & & & & & \\
\hline Content Feature (CF) & .298 & .418 & 1 & & & & & & & & \\
\hline Language Capability (LAC) & .294 & .236 & .360 & 1 & & & & & & & \\
\hline Interaction (I) & .276 & .469 & .499 & .324 & 1 & & & & & & \\
\hline Perceived Ease of Use (PE) & .280 & .419 & .322 & .375 & .416 & 1 & & & & & \\
\hline Attitude (AT) & .330 & .482 & .461 & .397 & .646 & .565 & 1 & & & & \\
\hline Extraversion (EX) & .026 & .056 & .099 & .023 & .128 & .127 & .054 & 1 & & & \\
\hline Agreeableness (AG) & .061 & .218 & .140 & .107 & .243 & .172 & .173 & .209 & 1 & & \\
\hline Conscientiousness (CO) & .098 & .157 & .186 & .171 & .112 & .129 & .155 & .041 & .404 & 1 & \\
\hline Neuroticism (NE) & .091 & .029 & .015 & .029 & .086 & .012 & .056 & .103 & .188 & .206 & 1 \\
\hline Openness to Experience (OE) & .104 & .125 & .117 & .020 & .077 & .067 & .042 & .043 & .236 & .187 & .207 \\
\hline
\end{tabular}


Table A5: Analysis of all effects in the final model

\begin{tabular}{|c|c|c|c|c|c|}
\hline & \multirow{2}{*}{ Variable } & \multirow{2}{*}{ Effect } & \multicolumn{2}{|c|}{ Intervening Variable } & \multirow{2}{*}{$\begin{array}{c}\text { Dependent Variable } \\
\text { Attitude (AT) }\end{array}$} \\
\hline & & & Content Feature & Perceived Ease of Use & \\
\hline \multirow{20}{*}{ 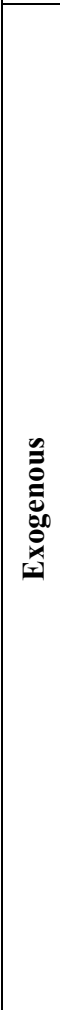 } & \multirow{4}{*}{$\begin{array}{l}\text { System } \\
\text { Functionality } \\
\text { (SF) }\end{array}$} & Direct & $.486 * * *(.513 \mathrm{~L})$ & $.334 * * *(.292 \mathrm{M})$ & Nil \\
\hline & & Indirect & Nil & Nil & $\begin{array}{c}\text { SF-PE-AT } \\
.086 * * *(.093 \mathrm{~S}) \\
\text { SF-CF-AT } \\
.063^{* *}(.067 \mathrm{~S})\end{array}$ \\
\hline & & Total Indirect & Nil & Nil & $.149 * *(.160 \mathrm{M})$ \\
\hline & & Total & $486 * * *(.513 \mathrm{~L})$ & $334 * * *(.292 \mathrm{M})$ & $.149 * *(.160 \mathrm{M})$ \\
\hline & \multirow{4}{*}{$\begin{array}{l}\text { Language } \\
\text { Capability } \\
\text { (LAC) }\end{array}$} & Direct & Nil & $.205 * * *(.259 \mathrm{M})$ & $.052(.081 \mathrm{~S})$ \\
\hline & & Indirect & Nil & Nil & $\begin{array}{c}\text { LAC-PE-AT } \\
.053^{* * *}(.082 \mathrm{~S})\end{array}$ \\
\hline & & Total Indirect & Nil & Nil & $.053 * * *(.082 \mathrm{~S})$ \\
\hline & & Total & Nil & $.205 * * *(.259 \mathrm{M})$ & $.105(.163 \mathrm{M})$ \\
\hline & \multirow{4}{*}{ In } & Direct & Nil & $.244 * * *(.218 \mathrm{M})$ & $.425 * * *(.465 \mathrm{M})$ \\
\hline & & Indirect & Nil & Nil & $\begin{array}{c}\text { I-PE-AT } \\
.063 * * *(.069 \mathrm{~S})\end{array}$ \\
\hline & & Total Indirect & Nil & Nil & $\begin{array}{c}\text { I-PE-AT } \\
.063^{* * *}(.069 \mathrm{~S})\end{array}$ \\
\hline & & Total & Nil & $.244 * * *(.218 M)$ & $.488 * * *(.534 \mathrm{~L})$ \\
\hline & \multirow{4}{*}{$\begin{array}{l}\text { Computer } \\
\text { Self-efficacy } \\
\text { (CSE) }\end{array}$} & Direct & Nil & Nil & $.049(.072 \mathrm{~S})$ \\
\hline & & Indirect & Nil & Nil & Nil \\
\hline & & Total Indirect & Nil & Nil & Nil \\
\hline & & Total & Nil & Nil & $.049(.072 S)$ \\
\hline & \multirow{4}{*}{$\begin{array}{l}\text { Extraversion } \\
(\mathrm{EX})\end{array}$} & Direct & Nil & $.054(.084 \mathrm{~S})$ & $-.034(-.064 S)$ \\
\hline & & Indirect & Nil & Nil & $\begin{array}{l}\text { EX-PE-AT } \\
.014(.027 \mathrm{~S})\end{array}$ \\
\hline & & Total Indirect & Nil & Nil & $.014(.027 \mathrm{~S})$ \\
\hline & & Total & Nil & $.054(.084 S)$ & $-.020(-.037 S)$ \\
\hline \multirow{8}{*}{ 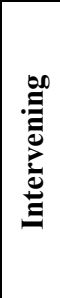 } & \multirow{4}{*}{$\begin{array}{l}\text { Content } \\
\text { Feature } \\
(\mathrm{CF})\end{array}$} & Direct & Nil & Nil & $.129 * *(.131 \mathrm{M})$ \\
\hline & & Indirect & Nil & Nil & Nil \\
\hline & & Total Indirect & Nil & Nil & Nil \\
\hline & & Total & Nil & Nil & $.129 * *(.131 \mathrm{M})$ \\
\hline & \multirow{4}{*}{\begin{tabular}{|l} 
Perceived \\
Ease \\
of Use \\
$(\mathrm{PE})$ \\
\end{tabular}} & Direct & Nil & Nil & $.258 * * *(.317 \mathrm{M})$ \\
\hline & & Indirect & Nil & Nil & Nil \\
\hline & & Total Indirect & Nil & Nil & Nil \\
\hline & & Total & Nil & Nil & $.258 * * *(.317 \mathrm{M})$ \\
\hline \multicolumn{6}{|c|}{$\begin{array}{l}\text { Notes: (a) Effects are presented using the same notations as described following Figure } 4 \text {; (b) The statistical signifi- } \\
\text { cance of indirect effects was determined using the heuristic from Cohen \& Cohen (1983); (c) The statistical signifi- } \\
\text { cance of the total of indirect effects and the total of all effects were determined by using nonparametric bootstrapping } \\
\text { with } 1,000 \text { random samples to estimate the standard error of the total. }\end{array}$} \\
\hline
\end{tabular}

\section{Biography}

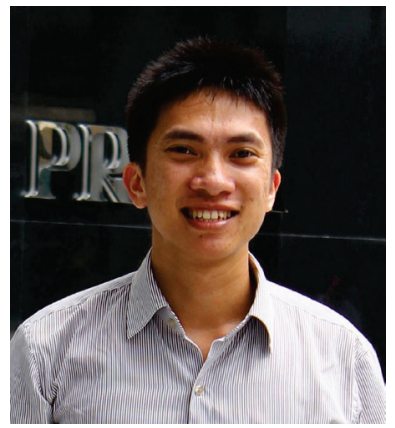

Khanh Ngo Nhu Tran is a Ph.D student at Vincent Mary School of Science and Technology, Assumption University, Thailand. He is a lecturer in Department of Information Technology, Dalat University, Vietnam and an instructor of Cisco Networking Academy program in Vietnam. The main research topics of his interested are Acceptance of Information Systems, E-learning and Data Science. His current research focuses on student's acceptance and adoption of blended elearning systems, effectiveness of multiple learning delivery methods combination. 